\title{
A propósito da investigação sobre cerâmica islâmica em Portugal
}

Isabel Inácio, Constança dos Santos, Catarina Coelho, Marco Liberato, Ana Sofia Gomes, Jacinta Bugalhão, Helena Catarino, Sandra Cavaco, Jaquelina Covaneiro, Isabel Cristina Fernandes, Susana Gómez e Maria José Gonçalves

\section{OpenEdition}

\section{Journals}

Edição electrónica

URL: http://journals.openedition.org/medievalista/1462

DOI: $10.4000 /$ medievalista.1462

ISSN: 1646-740X

\section{Editora}

Instituto de Estudos Medievais - FCSH-UNL

Refêrencia eletrónica

Isabel Inácio, Constança dos Santos, Catarina Coelho, Marco Liberato, Ana Sofia Gomes, Jacinta Bugalhão, Helena Catarino, Sandra Cavaco, Jaquelina Covaneiro, Isabel Cristina Fernandes, Susana Gómez e Maria José Gonçalves, « A propósito da investigação sobre cerâmica islâmica em Portugal », Medievalista [Online], 17 | 2015, posto online no dia 01 junho 2015, consultado no dia 30 abril 2019. URL : http://journals.openedition.org/medievalista/1462 ; DOI : 10.4000/medievalista.1462 
Título: A propósito da investigação sobre cerâmica islâmica em Portugal Autor(es): Isabel Inácio, Constança dos Santos, Catarina Coelho, Marco Liberato, Ana Sofia Gomes, Jacinta Bugalhão, Helena Catarino, Sandra Cavaco, Jaquelina Covaneiro, Isabel Cristina Fernandes, Susana Gómez, Maria José Gonçalves Universidade: Universidade de Coimbra Faculdade e Departamento / Unidade de Investigação: CEAACP-CAM / DGPC / IEM (FCSH-UNL) / FCT / UNIARQ / FLUC / Câmara Municipal de Tavira / Museu Municipal de Palmela / Câmara Municipal de Silves

Código Postal: 3000-395 COIMBRA

Cidade: Coimbra

País: Portugal

Contacto: isabelminacio@gmail.com; constancavs@gmail.com; catgcoelho@gmail.com; marcoliberato@hotmail.com; agomes@dgpc.pt; jacintabugalhao@gmail.com; hcatarino@fl.uc.pt; scavaco@ hotmail.com; jaquelinacovaneiro@ hotmail.com; isacrisff@gmail.com; susanagomez@sapo.pt; maria.goncalves@cm-silves.pt Fonte: Medievalista [Em linha]. Direc. José Mattoso. Lisboa: IEM.

Disponível em: http://www2.fcsh.unl.pt/iem/medievalista/

ISSN: 1646-740X

Data recepção do artigo: 5 de Março de 2014

Data aceitação do artigo: 8 de Julho de 2014

\section{Resumo}

As primeiras referências sobre cerâmica islâmica em Portugal remontam ao final do século XIX. A investigação evolui timidamente até aos anos 80 do século $\mathrm{XX}$, quando se assiste ao incremento dos estudos sobre a temática, impulsionado pelos projectos estruturantes de Mértola e Silves. Nos anos 90, este incremento intensifica-se e, na última década, a par de um maior número, alargam-se a diversidade e a dispersão geográfica de trabalhos e projectos, nomeadamente com origem em arqueologia urbana. 
A propósito da investigação sobre cerâmica islâmica em Portugal • Isabel Inácio, Constança dos Santos, Catarina Coelho, Marco Liberato, Ana Sofia Gomes, Jacinta Bugalhão, Helena Catarino, Sandra Cavaco, Jaquelina Covaneiro, Isabel Cristina Fernandes, Susana Gómez, Maria José Gonçalves

O projecto CIGA (Cerâmica Islâmica do Ġarb al-Andalus), iniciado em 2008, insere-se nesta dinâmica, promovendo a sistematização, problematização e divulgação de toda a informação dispersa e apresentando aqui uma síntese histórica dos estudos sobre cerâmica islâmica recolhida no território português, as suas principais tendências, os seus problemas, virtudes e as perspectivas futuras.

Palavras-chave: Cerâmica; período islâmico; história da arqueologia; Projecto CIGA.

\section{Abstract}

The first references on Islamic pottery in Portugal go back to the end of the nineteenth century. The modest evolution of the research until the 1980s was replaced by the development of the studies on this subject, pressed forward by the fundamental projects of Mértola and Silves. In the 1990s, this development was intensified and, in the last decade, the number, diversity and geographical dispersion of studies and projects was remarkable, particularly those originated from urban archaeology. The CIGA project (Cerâmica Islâmica do Ġarb al-Andalus), started in 2008, is part of this dynamics, promoting the systematization, the discussion and the diffusion of all the information and presenting here a composite paper about the studies on Islamic ceramics in Portugal, its main tendencies, problems, virtues and future perspectives.

Keywords: Ceramics; Islamic period; history of archeology; CIGA Project. 


\title{
A propósito da investigação sobre cerâmica islâmica em Portugal
}

\author{
Isabel Inácio, Constança dos Santos, Catarina Coelho, \\ Marco Liberato, Ana Sofia Gomes, Jacinta Bugalhão, \\ Helena Catarino, Sandra Cavaco, Jaquelina Covaneiro, \\ Isabel Cristina Fernandes, Susana Gómez, Maria José Gonçalves
}

\section{Nota introdutória}

A investigação arqueológica sobre a cerâmica islâmica do Ġarb al-Andalus é uma realidade recente e que revela muitas debilidades, quer ao nível da regularidade de estudo e publicação de conjuntos cerâmicos, quer ao nível da reflexão, conceptualização e síntese dos conhecimentos disponíveis. A análise histórica da evolução dos estudos permite identificar problemas e potencialidades e perspectivar linhas de trabalho futuras. Neste contexto, enquadra-se a contribuição do projecto CIGA para um ensaio histórico sintético sobre a evolução do estudo da cerâmica islâmica em Portugal, elaborado na sequência de anteriores experiências com idêntico propósito ${ }^{1}$.

\footnotetext{
${ }^{1}$ CATARINO, Helena - "Arqueologia do período islâmico em Portugal: breve perspectiva". in $O$ Arqueólogo Português. Lisboa. Série IV. 13/15, 1995/1997, pp. 457-484; GÓMEZ MARTÍNEZ, Susana "A Cerâmica no Gharb al-Ândaluz". in Portugal Islâmico - Os últimos sinais do Mediterrâneo. Lisboa: Museu Nacional de Arqueologia, 1998, pp. 121-131; CATARINO, Helena - "Arqueologia Medieval: o estado da 'arte' e novas perspectivas". in ENCARNAÇ̃̃O, José d' (ed.) - As Oficinas da História. Coimbra: Ed. Colibri/FLUC, 2002, pp. 131-148; GOMES, Rosa Varela - "O século XX e a Arqueologia Muçulmana em Portugal". in Arqueologia \& História. Lisboa. 54 (2002), pp. 203-220; FERNANDES, Isabel Cristina F. - "Arqueologia Medieval em Portugal: 25 anos de investigação". in Portugália. Porto. Nova Série, Vol. XXVI (2005), pp. 149-173; GÓMEZ MARTÍNEZ, Susana - Cerámica Islámica de Mértola: producción y comercio. Madrid: Servicio de Publicaciones de la Universidad Complutense de Madrid, 2006.2 Disponível em http://cisne.sim.ucm.es/search*spi $\sim$ S7/X?SEARCH=susana+gomez+martinez\&searchscope=7\&SORT=D ; CATARINO, Helena - "Arqueologia da Antiguidade tardia e do período islâmico do Algarve na época
} 
A propósito da investigação sobre cerâmica islâmica em Portugal • Isabel Inácio, Constança dos Santos, Catarina Coelho, Marco Liberato, Ana Sofia Gomes, Jacinta Bugalhão, Helena Catarino, Sandra Cavaco, Jaquelina Covaneiro, Isabel Cristina Fernandes, Susana Gómez, Maria José Gonçalves

\section{Do final do século XIX a 1970: os primeiros passos}

Quando se recua ao século XIX e aos trabalhos pioneiros da Arqueologia em Portugal, para cotejar referências sobre vestígios da época islâmica, deparamo-nos com um quase vazio de informações. Contudo, a qualidade tecnológica das produções cerâmicas e, sobretudo, as particularidades de algumas das suas concepções estéticas, desde cedo procuradas pelos antiquários, não deixaram indiferentes historiadores e arqueólogos, ainda que apenas evidenciassem a sua importância no âmbito das manifestações artísticas, no capítulo das artes decorativas.

Mesmo sem fazermos uma pesquisa muito exaustiva, podemos constatar que nas primeiras explorações arqueológicas, sobretudo no Alentejo e no Algarve, apareceram vestígios muçulmanos, nem sempre porém catalogados correctamente. Ainda assim, um dos arqueólogos que mais mencionou cerâmicas islâmicas foi Estácio da Veiga (18281891) que, nas Antiguidades Monumentaes do Algarve, teceu, inclusivamente, considerações laudatórias sobre o período em questão e sobre as "louças árabes" que encontrou nos sítios que identificou e explorou ${ }^{2}$.

Sobre essas "louças" e a título de exemplo, o arqueólogo algarvio explicou que, em Cacela: "não faltavam fragmentos dos preciosos jarrões ornamentados de relevo, que eram cingidos de inscripções cúficas"3 ${ }^{3}$ e a propósito de Torre dos Frades (Cacela), falou das "louças grosseiras, louças vidradas e vasos de barro ammarelado com pinturas ordinárias [...]. Todas [...] capituladamente árabes" ${ }^{4}$. Sobre os achados no sítio de Vale Caranguejeiro (entre Tavira e Vila Real de Santo António), descreve e indica paralelos para fragmentos de alcatruzes: "de barro amarellado, com caneluras estreitas em relevo, similares aos alcatruzes inteiros que em Silves foram extrahidos da cisterna dos cães”, e

de Estácio da Veiga”. in Xelb. Silves. n. ${ }^{\text {7 }}$ 7, 2007, pp. 179-194; GÓMEZ MARTíNEZ, Susana "Reflexão crítica sobre o estado da investigação para o período medieval islâmico no Algarve". Xelb. Silves. n. ${ }^{\circ}$ 10, 2010, pp. 497-508; COVANEIRO, Jaquelina et alii - "Cerâmica islâmica em Portugal: 150 anos de investigação". Arqueologia em Portugal. 150 Anos. Lisboa: Associação dos Arqueólogos Portugueses, 2013, pp. 73-80.

${ }^{2}$ CATARINO, Helena - "Arqueologia da Antiguidade Tardia...".

${ }^{3}$ VEIGA, Sebastião Philippes Martins Estácio da - Antiguidades monumentaes do Algarve. Vol. II. Lisboa: Imprensa Nacional, 1887, pp. 401 e 422-423.

${ }^{4}$ Ibidem, p. 425. 
A propósito da investigação sobre cerâmica islâmica em Portugal • Isabel Inácio, Constança dos Santos, Catarina Coelho, Marco Liberato, Ana Sofia Gomes, Jacinta Bugalhão, Helena Catarino, Sandra Cavaco, Jaquelina Covaneiro, Isabel Cristina Fernandes, Susana Gómez, Maria José Gonçalves

acrescenta que "no Algarve são ainda usadas as noras, os chamados 'engenhos mouriscos', que sem dúvida alguma os mouros introduziram como outros muitos melhoramentos próprios da sua mui adiantada civilização"s.

Reflexo da apreciação elogiosa sobre essa época é o que escreve acerca de Silves: “a soberba capital da província ou principado de Al-faghar" e seus importantes monumentos arquitectónicos, epigráficos e cerâmicas ${ }^{6}$. Numa óptica de "interpretação estratigráfica", diz que no Ilhéu do Rosário (Silves) apareceram "muitas louças árabes vidradas e logo abaixo louças romanas"7. Sobre os vestígios de Vila Velha de Alvor, também indica "muitos pedaços de louça árabe vidrada, de que foram mestres na península os taes mouros, que os nossos chronistas designam quase sempre com o

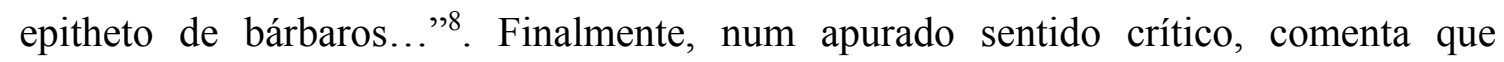
"embora o fanatismo dos nossos chronistas quizesse desauctorisar essa esmerada civilização [...] taxando-a de bárbara [...], mais bárbaros foram os que no furor da intolerância destruíram tudo quanto essa civilização havia erigido no torrão peninsular"9.

Similarmente, nas explorações arqueológicas de Mértola levadas a cabo pelo mesmo investigador e compiladas na obra monográfica Memórias das Antiguidades de Mértola (1880), são de realçar, no capítulo intitulado Epocha Arabe, as "louças que deveriam ser comuns nos usos da vida doméstica, que são, a meu ver, as que mais conviria coligir todas as vezes que os seus próprios fragmentos se manifestassem em condições propícias ao estudo"10. Critica, ainda, o facto de em Portugal existir uma pobreza de estudos sobre cerâmica islâmica e se estudarem apenas os objectos de luxo ${ }^{11}$.

Outros seguiram o exemplo do arqueólogo de Tavira, como foi o caso de António dos Santos Rocha (1853-1910), que procedeu a várias explorações arqueológicas no Algarve. Em 1895, escavou os silos de Bensafrim, já conhecidos de Estácio da Veiga,

\footnotetext{
5 Ibidem, p. 422.

${ }^{6}$ Ibidem, p. 357.

${ }^{7}$ Ibidem, pp. 351-352.

${ }^{8}$ Ibidem, p. 343.

${ }^{9}$ IDEM - Antiguidades Monumentaes do Algarve. Vol. III. Lisboa: Imprensa Nacional, 1889, p. 53.

${ }^{10}$ Idem - Memoria das antiguidades de Mértola observadas em 1877 e relatadas por... Lisboa: Imprensa Nacional, 1880, p. 162.

${ }^{11}$ Appud CATARINO, Helena - “Arqueologia do período islâmico...”, pp. 160-161.
} 
A propósito da investigação sobre cerâmica islâmica em Portugal • Isabel Inácio, Constança dos Santos, Catarina Coelho, Marco Liberato, Ana Sofia Gomes, Jacinta Bugalhão, Helena Catarino, Sandra Cavaco, Jaquelina Covaneiro, Isabel Cristina Fernandes, Susana Gómez, Maria José Gonçalves

corrigindo a avaliação deste: "Divergindo o modo de ver do meu bom amigo, a cerâmica é, sem contestação, árabe"12. Na verdade, dos desenhos apresentados, só os das figuras 29, 30 e 31 são de época islâmica, sendo os restantes posteriores. Para além das descobertas em Santa Olaia e outras estações arqueológicas beirãs, as escavações no primeiro sítio permitiram-lhe identificar várias fases de ocupação ("uns povoados sobrepostos"), incluindo os restos de alicerces das estruturas medievais. E sobre algumas das cerâmicas pintadas aí recolhidas, questiona se "Seriam árabes as louças pintadas de Santa Olaia? A afirmativa também não repugnava. Ali existiu um castelo, que foi ocupado pelos árabes. Pertencia à linha das fortificações avançadas que defendiam Coimbra"13.

Outro pioneiro e grande vulto da arqueologia nacional, Leite de Vasconcelos (18581941), foi, aparentemente, pouco atento às cerâmicas islâmicas, embora não deixasse de mencionar vestígios dessa época. Para além de epígrafes e moedas, refere sobretudo candis (lucernas ou candeias arábicas), por exemplo de Torre d'Ares e de Faro ${ }^{14}$, de Silves e de Cacela, neste caso de disco impresso e de bronze ${ }^{15}$. Refiram-se, ainda, as suas observações sobre o sítio da Cola (Ourique), que fez numa "visita muito fugitiva", colhendo "apontamentos breves", mas dizendo que o sítio "merecia [...] uma expedição arqueológica que explorasse metodicamente o terreno e tirasse boas plantas e fotografias". Nessas notas, indica fustes de colunas e pedras aparelhadas, "tudo certamente da época romana; e bem assim: tijolos muito grossos, como os romanos; um gargalo ornamentado (fig. 7); imbrices. Não encontrei tégulas, mas decerto, bem procuradas, apareceriam"16. Muito embora atribua esses vestígios ao período romano, a verdade é que um dos desenhos que ilustra (fig. 7) pertence ao fragmento de uma talha estampilhada, do mesmo tipo dos "jarrões ornamentados de relevo" que Estácio da Veiga elogiava entre as louças arábicas de Cacela. Outro exemplo, porém nessa altura

12 ROCHA, António Santos - "Notícia de alguns silos e louças árabes do Algarve". in Boletim da Sociedade Archeologica Santos Rocha. Figueira da Foz. Vol. I: 1 (1904), pp. 20-21 e Est. II e III.

13 Idem - Memórias e explorações arqueológicas. Memórias sobre a Antiguidade. (Acta Universitatis Conimbrigensis, Vol. II). Coimbra: Biblioteca Geral da Universidade de Coimbra, 1971. p. 143.

${ }^{14}$ VASCONCELOS, José Leite - “Coisas Velhas". in O Archeologo Português. Lisboa. Vol. XXII (1917), p. 26.

${ }^{15}$ Idem - "Candeias árabes do Algarve". in O Archeologo Português. Lisboa. Vol. VII (1902), pp. 119123.

${ }^{16}$ Idem - "Excursão pelo Baixo Alentejo". in O Archeologo Português. Lisboa. Vol. XXIX (1933), pp. 239-240.

Medievalista online № 17 I Jane iro - Junho 2015 (C) $\mathbb{E M}$ - Instituto de Estudos Me die va is 6 www2.fc sh.unl.pt/ie m/me die va lista 
A propósito da investigação sobre cerâmica islâmica em Portugal • Isabel Inácio, Constança dos Santos, Catarina Coelho, Marco Liberato, Ana Sofia Gomes, Jacinta Bugalhão, Helena Catarino, Sandra Cavaco, Jaquelina Covaneiro, Isabel Cristina Fernandes, Susana Gómez, Maria José Gonçalves

menos fácil de identificar como islâmico, é a panela proveniente da mina de cobre da Serra de Caveira (Canal Caveira): "um vaso de barro, um tanto grosseiro, espécie de panela ou olla, com duas asas"17.

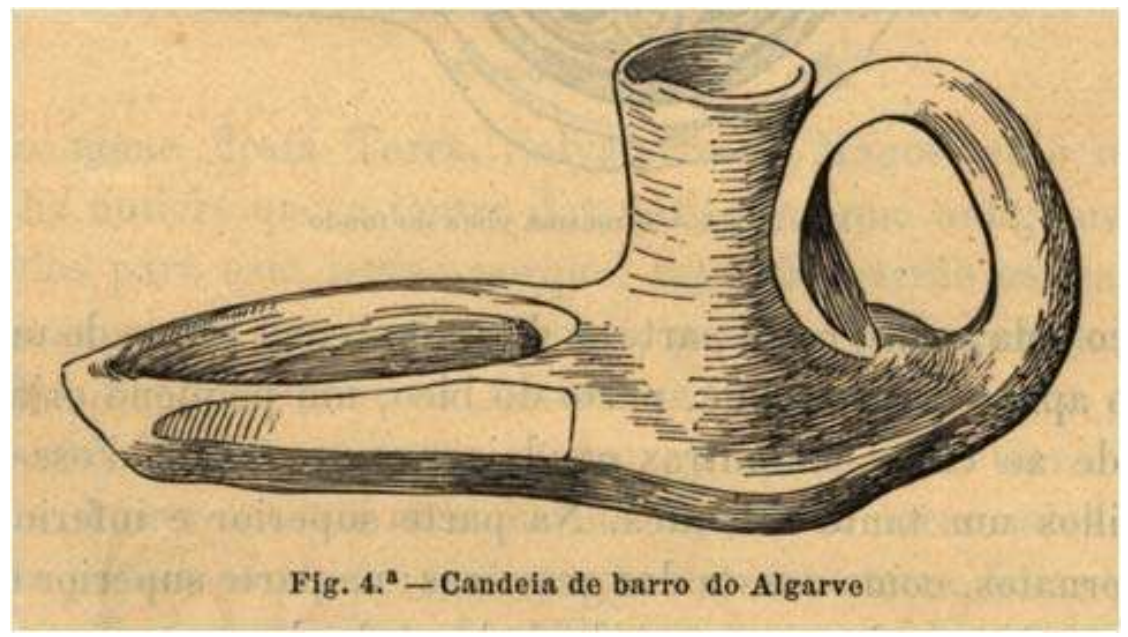

Figura 1. Desenho de candil algarvio. ${ }^{18}$

A partir da década de 40 do século XX, a revista Arquivo de Beja abre nova etapa na divulgação de trabalhos regionais, mais ou menos sistemáticos para o Baixo Alentejo, e cabe a Abel Viana, figura incontornável da arqueologia alentejana e algarvia, encetar pesquisas nas épocas visigótica e islâmica. Salienta-se o seu estudo sobre peças árabes do Museu Regional de Lagos, em colaboração com José Formosinho e Octávio Veiga Ferreira (1953). Este arqueólogo vianense radicado em Beja, também refere achados de "cerâmica árabe" junto da muralha desta cidade alentejana e estuda os objectos depositados no Museu Regional de Beja, incluindo cerâmica islâmica, embora alguns dos exemplares descritos sejam em realidade objectos de época moderna ${ }^{19}$. Das escavações que realiza no Castro da Cola (Ourique) a partir de 1958, divulga a planta das estruturas e cerâmicas árabes, embora ainda sem descrições detalhadas ${ }^{20}$.

17 Idem - "Excursão arqueológica à Extremadura Transtagana". in O Archeologo Português. Lisboa. Vol. XIX (1914), p. 311, Fig. 31.

${ }^{18}$ Idem - "Coisas Velhas...", p. 126.

19 VIANA, Abel - "Museu regional de Beja. Alguns objectos da Idade do Bronze, da Idade do Ferro e da Época Romana; cerâmica argárica; cerâmica árabe”. in Arquivo de Beja. Beja. Vol. II (1945), pp. 333-339.

${ }^{20}$ Idem - "Castro de Nossa Senhora da Cola (Ourique)". in Arquivo de Beja. Beja. Vol. XV (1958), pp. 25-35; idem - "Notas históricas, arqueológicas e etnográficas do Baixo Alentejo. 1. Castro de Nossa 
A propósito da investigação sobre cerâmica islâmica em Portugal • Isabel Inácio, Constança dos Santos, Catarina Coelho, Marco Liberato, Ana Sofia Gomes, Jacinta Bugalhão, Helena Catarino, Sandra Cavaco, Jaquelina Covaneiro, Isabel Cristina Fernandes, Susana Gómez, Maria José Gonçalves

Finalmente, em 1962, surge a sua obra Algumas noções elementares de arqueologia prática, que inclui um capítulo sobre vestígios de época islâmica.

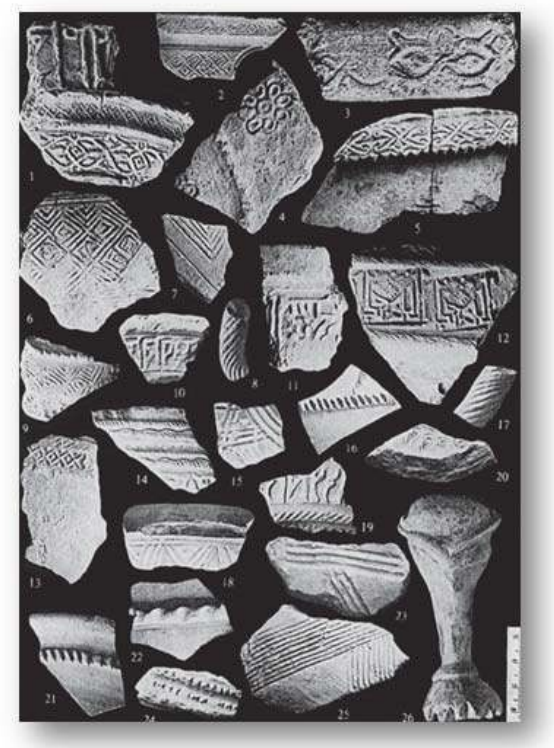

Figura 2. Cerâmicas islâmicas do Castro da Cola, Ourique. ${ }^{21}$

\section{De 1970 a 1998: afirmação da arqueologia islâmica e da cerâmica como seu fóssil- director}

Os anos 70 foram determinantes para a afirmação da arqueologia islâmica em Portugal. A intervenção-marco que definiu, no terreno, o início do interesse pela cultura material islâmica foi a do Cerro da Vila (Vilamoura), dirigida por José Luís de Matos a partir de 1971. Os registos de cerâmica muçulmana em contexto têm aqui o seu pioneirismo. É também este arqueólogo que então procede ao reconhecimento do espólio islâmico do Museu de Beja, das colecções de Loulé e de Silves no Museu Nacional de Arqueologia e de materiais no Castro da Cola. A ele se deve a regência da cadeira de Arqueologia Árabe Medieval (1977/78) na Faculdade de Letras da Universidade de Lisboa, onde a

Senhora da Cola". Arquivo de Beja. Beja. Vol. XVI, 1959, pp. 3-24; idem - "Notas históricas arqueológicas e etnográficas do Baixo Alentejo. Senhora da Cola". in Arquivo de Beja. Beja. Vol. XVII (1960), pp. 138-226.

${ }^{21}$ Ibidem, Est. XXVIII. 
A propósito da investigação sobre cerâmica islâmica em Portugal • Isabel Inácio, Constança dos Santos, Catarina Coelho, Marco Liberato, Ana Sofia Gomes, Jacinta Bugalhão, Helena Catarino, Sandra Cavaco, Jaquelina Covaneiro, Isabel Cristina Fernandes, Susana Gómez, Maria José Gonçalves

cerâmica muçulmana assume protagonismo, proporcionando-se aos alunos o contacto directo com esses materiais e o ensaio do respectivo desenho arqueológico. Não esqueçamos que é em 1978 que Guillermo Rosselló Bordoy publica o Ensayo de sistematización de la cerámica árabe en Mallorca, determinante para a uniformização de critérios de análise morfológica da cerâmica islâmica.

Pouco depois (1979/80) arranca o projecto de Mértola, encabeçado por Cláudio Torres e será a partir desta vila alentejana que crescentemente se torna evidente a dimensão dos vestígios islâmicos no território português, com destaque para a cerâmica. As investigações arqueológicas iniciais de Mértola centraram-se no criptopórtico-cisterna e no bairro islâmico, alargando-se depois a vários pontos do povoado. $\mathrm{O}$ significado do espólio cerâmico aí exumado, a sua qualidade e quantidade e o seu bom estado de conservação, justificaram que se tornasse o símbolo do Campo Arqueológico de Mértola e uma montra privilegiada para o exterior. O catálogo Cerâmica Islâmica Portuguesa (Torres, 1987) foi a primeira publicação chamativa de Mértola e um ícone da arqueologia islâmica em Portugal e dos estudos de cerâmica deste período.

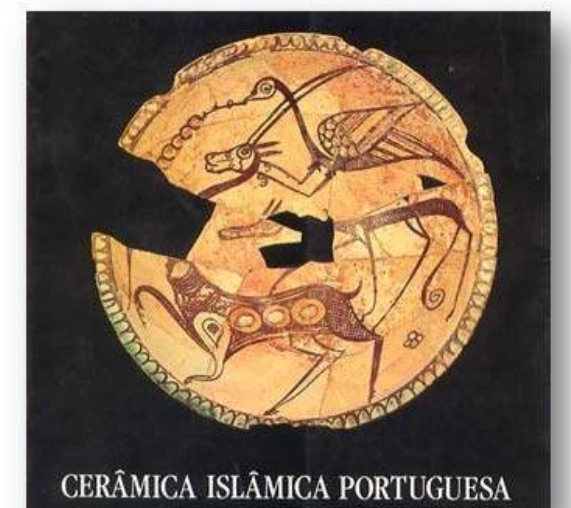

Figura 3. Capa do catálogo Cerâmica islâmica portuguesa de Cláudio Torres, editado em 1987, pelo Campo Arqueológico de Mértola.

Nesse mesmo ano realiza-se, em Lisboa, com organização do Campo Arqueológico de Mértola e da Fundação Calouste Gulbenkian, o IV Congresso Internacional A Cerâmica Medieval no Mediterrâneo Ocidental22. O contacto com o universo de estudos

${ }^{22}$ SILVA, Luís Alves da; MATEUS, Rui (eds.) - Actas do IV Congresso Internacional A cerâmica medieval no Mediterrâneo Ocidental. Mértola: Campo Arqueológico de Mértola, 1991. 
A propósito da investigação sobre cerâmica islâmica em Portugal • Isabel Inácio, Constança dos Santos, Catarina Coelho, Marco Liberato, Ana Sofia Gomes, Jacinta Bugalhão, Helena Catarino, Sandra Cavaco, Jaquelina Covaneiro, Isabel Cristina Fernandes, Susana Gómez, Maria José Gonçalves

ceramológicos de Espanha, Itália e França, com destaque para o levante espanhol, transportou-nos para uma dimensão de análise comparativa, de maior reconhecimento das potencialidades destas produções e da necessidade de investir mais nesta área. Apresentaram-se, neste fórum, cerâmicas muçulmanas de Mértola, de Beja, do Cerro da Vila, de Silves e as primeiras peças de Cascais. Merece ainda destaque o trabalho de Margarida Ribeiro (1991) sobre terminologia cerâmica e fontes escritas.

A actividade arqueológica em Silves, liderada por Rosa Varela Gomes, enquadrou trabalhos no poço-cisterna almóada, no início dos anos 80 e, a partir de 1984, no castelo de Silves. Os primeiros resultados são publicados na Xelb, 1, em estudo intitulado Cerâmicas Muçulmanas do Castelo de Silves ${ }^{23}$, que trata o espólio cerâmico a partir da sua contextualização estratigráfica. A este estudo sucedem-se numerosos outros, nos quais a autora explora as diversificadas manifestações materiais da cerâmica islâmica de Silves. Em 1991 publica novo estudo sobre peças muçulmanas esmaltadas, polícromas e de reflexo metálico do castelo de Silves ${ }^{24}$.

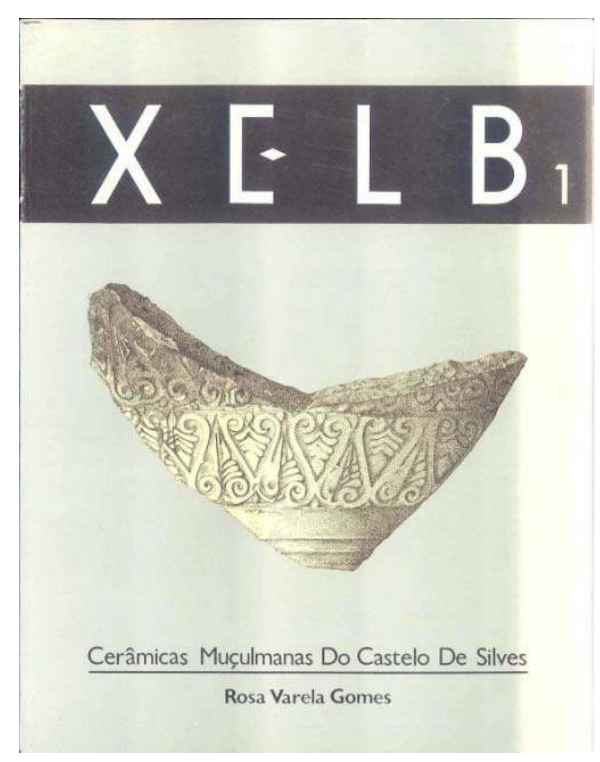

Figura 4. Capa da obra Cerâmicas Muçulmanas do Castelo de Silves de Rosa Varela Gomes, primeira monografia sobre cerâmica islâmica editada em Portugal (1988), no primeiro número da revista Xelb (Câmara Municipal de Silves).

23 GOMES, Rosa Varela - Cerâmicas Muçulmanas do Castelo de Silves (Xelb, 1). Silves: Câmara Municipal de Silves, 1988.

${ }^{24}$ GOMES, Rosa Varela - "Cerâmicas muçulmanas, orientais e orientalizantes do Castelo de Silves (peças esmaltadas, policromas e de reflexo metálico)". in Estudos Orientais. Lisboa. Vol. II (1991), pp. 13-39.

Medievalista online № 17। Ja ne iro - Junho 2015 (C) EM - Instituto de Estudos Me die va is 10 www2.fc sh.unl.pt/ ie $\mathrm{m} / \mathrm{me}$ die va lista 
A propósito da investigação sobre cerâmica islâmica em Portugal • Isabel Inácio, Constança dos Santos, Catarina Coelho, Marco Liberato, Ana Sofia Gomes, Jacinta Bugalhão, Helena Catarino, Sandra Cavaco, Jaquelina Covaneiro, Isabel Cristina Fernandes, Susana Gómez, Maria José Gonçalves

Ainda no Algarve, importa referir a precoce escavação de Helena Catarino em Vale de Bôto (1981) e a sua investigação nos castelos de Alcoutim (1984), de Paderne (em $1987)^{25}$ e de Salir (também em 1987), com bons resultados ao nível do espólio cerâmico. O estudo de fortificações e do povoamento rural islâmico por Helena Catarino constituiu-se aliás como um projecto de duração alargada que resulta numa primeira síntese, apresentada em 1988. No final desta década e nos quinze anos seguintes, merecem também referência os trabalhos desenvolvidos por Teresa Gamito, tanto em meio urbano como rural, que incluem menção aos conjuntos cerâmicos ${ }^{26}$.

O impulso mais significativo, em termos de divulgação de estudos, a partir de 1992, é dado com a regular publicação da revista Arqueologia Medieval, pelo Campo Arqueológico de Mértola. De temática variada, dedica contudo um espaço significativo à divulgação de artigos sobre cerâmica islâmica ou sobre resultados de intervenções arqueológicas onde esse tipo de espólio é destacado. Para além de Mértola, com múltiplos artigos referenciados (assinados por Cláudio Torres, Santiago Macias, Miguel Rego, Susana Gómez Martínez e outros - 1992, 1993, 1995, 1996, 1997), através dos cinco primeiros números desta publicação periódica passaram a conhecer-se cerâmicas islâmicas de Silves ${ }^{27}$, de Juromenha ${ }^{28}$, do Montinho das Laranjeiras (Alcoutim) ${ }^{29}$, de Mesas do Castelinho (Almodôvar) ${ }^{30}$, de Paderne $^{31}$, de Alcácer do $\mathrm{Sal}^{32}$, de Milreu $(\text { Estói })^{33}$.

\footnotetext{
${ }^{25}$ Publicada em 1994: CATARINO, Helena - "O Castelo de Paderne (Albufeira: resultados da primeira intervenção arqueológica". in Arqueologia Medieval. Porto. n. 33 (1994), pp. 73-88.

${ }^{26}$ GAMITO, Teresa Júdice - O Algarve e o Magreb (711 - 1249). Faro: Universidade do Algarve, 2003.

${ }^{27}$ MATOS, José Luís de - "Cerâmicas muçulmanas do Castelo de Silves". in Arqueologia Medieval. Mértola. n. ${ }^{\circ} 1$ (1992), pp. 229-230.

${ }^{28}$ CORREIA, Fernando; PICARD, Cristophe - "Intervenção arqueológica no Castelo da Juromenha". in Arqueologia Medieval. Porto. n. ${ }^{\circ} 1$ (1992), pp. 71-89.

${ }^{29}$ COUTINHO, Hélder M. R. - "Cerâmica Muçulmana no Montinho das Laranjeiras". in Arqueologia Medieval. Porto. n. ${ }^{\circ}$ (1993), pp. 39-54.

30 FABIÃO, Carlos; GUERRA, Amílcar - "Uma fortificação Omíada em Mesas do Castelinho (Almodôvar)". in Arqueologia Medieval. Porto. n. ${ }^{\circ} 2$ (1993), pp. 85-102.

${ }^{31}$ CATARINO, Helena - "O Castelo de Paderne... ".

${ }^{32}$ CARVALHO, António Rafael; Faria, João Carlos - "Cerâmicas muçulmanas do Museu Municipal de Alcácer do Sal". in Arqueologia Medieval. Porto. n. 3 (1994), pp. 101-111.

${ }^{33}$ TEICHNER, Félix - "Acerca da Vila Romana de Milreu/Estoi. Continuidade da ocupação na época árabe". in Arqueologia Medieval. Porto. n. ${ }^{\circ} 3$ (1994), pp. 89-100.
} 


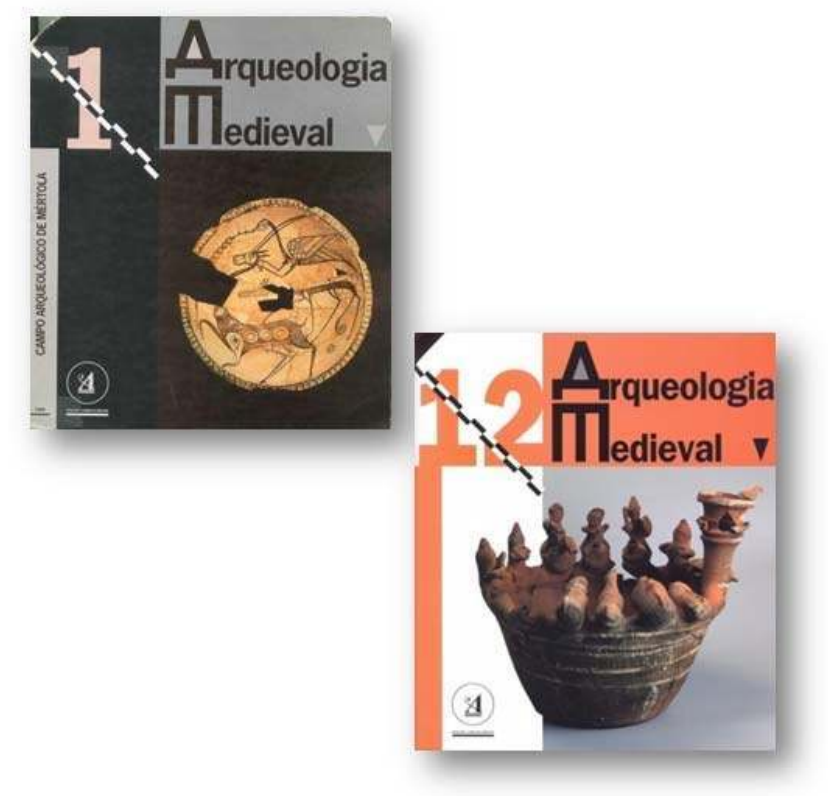

Figura 5. Capas dos números 1 (1992) e 12 (2012) da revista Arqueologia Medieval, editada pelo Campo Arqueológico de Mértola.

Ainda em Mértola, os estudos específicos sobre cerâmica sofrem um impulso considerável a partir dos anos 90 pela mão de Susana Gómez Martínez (culminando na sua tese de doutoramento ${ }^{34}$ ), trabalho que se prolonga em numerosas colaborações com outros investigadores sobre conjuntos cerâmicos islâmicos de diversos sítios do Ġarb alAndalus. Já em 1996, a publicação dos resultados das escavações no bairro da alcáçova por Santiago Macias, consagrou a relevância dos conjuntos cerâmicos desta vila alentejana para o conhecimento do quotidiano doméstico das populações islâmicas medievais do Ġarb.

Após as primeiras intervenções de Lisboa, nos anos 80, assiste-se na década de 90, ao boom da arqueologia urbana. Para além das cidades já referidas, Santarém, Torres Vedras, Sintra, Almada, Palmela, Alcácer do Sal, Juromenha, Évora, Moura, Silves e Tavira são exemplos de dinâmica na investigação arqueológica do período islâmico. Vários encontros de arqueologia urbana (1985, Setúbal; 1994, Braga; Almada, 1997)

34 GÓMEZ MARTÍNEZ, Susana - Cerámica Islámica de Mértola: producción y comercio. Madrid: Servicio de Publicaciones de la Universidad Complutense de Madrid, 2006. 
A propósito da investigação sobre cerâmica islâmica em Portugal • Isabel Inácio, Constança dos Santos, Catarina Coelho, Marco Liberato, Ana Sofia Gomes, Jacinta Bugalhão, Helena Catarino, Sandra Cavaco, Jaquelina Covaneiro, Isabel Cristina Fernandes, Susana Gómez, Maria José Gonçalves

dão conta desta tendência e veiculam alguma informação sobre materiais cerâmicos islâmicos, nomeadamente de Silves ${ }^{35}$, de Alcácer do $\mathrm{Sal}^{36}$ e de $\mathrm{Almada}^{37}$.

Os trabalhos arqueológicos dos anos 90, em Lisboa, permitiram definir ocupações islâmicas notáveis na Sé Catedral, no castelo de S. Jorge e na baixa pombalina nomeadamente, no Núcleo Arqueológico da Rua dos Correeiros/BCP (NARC), no Mandarim Chinês e na Praça da Figueira -, com resultados muito interessantes no que respeita ao espólio cerâmico, publicados sobretudo a partir de finais da década. A investigação das cerâmicas islâmicas do NARC e do Mandarim Chinês iniciou-se em 1997 no âmbito do projecto POILIX ${ }^{38}$.

Ainda na região de Lisboa e no curso do baixo e do médio Tejo, há que mencionar os artigos "Silos medievais de Caparide"39, "Almada medieval-moderna. Um projecto de investigação" ${ }^{40}$, as escavações na Rua da Judiaria, Almada ${ }^{41}$, as escavações no castelo de Povos - Vila Franca de Xira ${ }^{42}$, com cerâmicas publicadas por Carlos Banha ${ }^{43}$, as escavações no castelo de Sintra, por Catarina Coelho (2000 e 2002) e as de Santarém, entre 1984 e 1987, com 26 fossas registadas e que forneceram um conjunto apreciável de vasilhame de época muçulmana ${ }^{44}$.

${ }^{35}$ GOMES, Rosa Varela; GOMES, Mário Varela - "Cerâmicas estampilhadas muçulmanas e mudéjares, do poço-cisterna de Silves”. in Actas do I Encontro Nacional de Arqueologia Urbana, Setúbal, 1985 (Trabalhos de Arqueologia, 3). Lisboa: IPPC, 1986, pp. 127-141.

${ }^{36}$ PAIXÃO, António; FARIA, João Carlos; CARVALHO, António Rafael - "O Castelo de Alcácer do Sal. Um projecto de arqueologia urbana". in Encontro de Arqueologia Urbana (Bracara Augusta, vol. XLV. n. ${ }^{\circ}$ 97 (110). Braga, 1994, pp. 215-264.

${ }^{37}$ BARROS, Luís; ESPÍRITO SANTO, Paulo; ANTUNES, L. P. - "Rua da Judiaria (Almada). Notícia preliminar". in Encontro de Arqueologia Urbana (Bracara Augusta, vol. XLV. n. 97 (110), 1994, pp. 201214.

${ }^{38}$ BUGALHÃO, Jacinta; FOLGADO, Deolinda - "O arrabalde ocidental da Lisboa islâmica: urbanismo e produção oleira”. in Arqueologia Medieval. Porto. n. 7 (2001), pp. 111-145.

39 RODRIGUES, Severino; CABRAL, João - "Silos medievais de Caparide". in Arquivo de Cascais. Cascais. n. 9 (1990), pp. 63-73.

40 SABROSA, Armando; ESPÍRITO SANTO, Paulo - "Almada Medieval/Moderna, um projecto de investigação”. in Al-madan. Almada. 2. Série, n. 1 (1992), pp. 5-12.

${ }^{41}$ BARROS, Luís; ESPÍRITO SANTO, Paulo; ANTUNES, L. P. - “Rua da Judiaria...”.

42 CALAIS, Cristina - "Outeiro de Povos: resultado preliminar das primeiras intervenções arqueológicas". in Cira. Vila Franca de Xira. n. ${ }^{\circ} 7$ (1998), pp. 47-74.

${ }^{43}$ BANHA, Carlos Manuel dos Santos - "As cerâmicas do Alto do Senhor da Boa Morte (Povos): estudo preliminar”. in Cira. Vila Franca de Xira. n. ${ }^{o} 7$ (1995-1997), pp. 75-109.

44 VIEGAS, Catarina; ARRUDA, Ana Margarida - “Cerâmicas Islâmicas da Alcáçova de Santarém”. in Revista Portuguesa de Arqueologia. Lisboa. n. ${ }^{\circ}$ 2: 2 (1999), pp. 105-186. 
A propósito da investigação sobre cerâmica islâmica em Portugal • Isabel Inácio, Constança dos Santos, Catarina Coelho, Marco Liberato, Ana Sofia Gomes, Jacinta Bugalhão, Helena Catarino, Sandra Cavaco, Jaquelina Covaneiro, Isabel Cristina Fernandes, Susana Gómez, Maria José Gonçalves

Junto à foz do Sado, o castelo de Palmela foi objecto de intervenção arqueológica desde 1992, sob direcção de Isabel Cristina Fernandes, com registo de cerâmicas em contexto, num arco cronológico alargado até à segunda metade do séc. XII ${ }^{45}$. Ao longo da linha de costa da Arrábida, em Setúbal, Creiro, Lapa do Fumo e Sesimbra foram registadas algumas cerâmicas muçulmanas. A intervenção no castelo de Alcácer do Sal forneceu conjuntos cerâmicos de grande interesse, sobretudo para a fase almóada ${ }^{46}$.

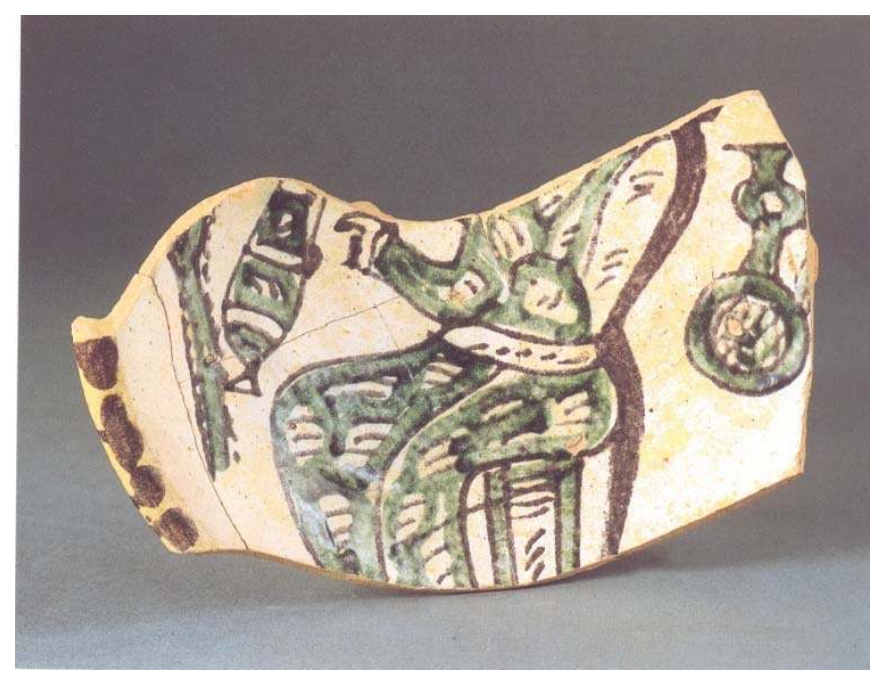

Figura 6. Taça do sedente em verde e manganês proveniente das escavações do Castelo de Palmela dirigidas por Isabel Cristina Fernandes.

O conhecimento da cerâmica islâmica proveniente do meio rural ganhou expressão com o extenso estudo do Algarve oriental islâmico, por Helena Catarino: O Algarve Oriental durante a ocupação islâmica. Povoamento rural e recintos fortificados (1998), tratando as intervenções iniciadas na década anterior, nos castelos de Salir, Relíquias, Castelo Velho de Alcoutim e as prospecções nas regiões envolventes. O espólio cerâmico, da fase omíada à almóada, é estudado com o detalhe que a sua importância exigia, tanto no contexto estratigráfico como em termos morfológicos.

\footnotetext{
${ }^{45}$ FERNANDES, Isabel Cristina; CARVALHO, António Rafael - "Cerâmicas muçulmanas do Castelo de Palmela”. in Actes du VI Colloque International sur la Céramique Médiévale in Méditerranée. Aix-enProvence: Narrations Editions, 1997, pp. 327-335; FERNANDES, Isabel Cristina - "Uma taça islâmica com decoração antropomórfica proveniente do Castelo de Palmela". in Arqueologia Medieval. Porto. n. 6 (1999), pp. 79-99; idem - O Castelo de Palmela, do islâmico ao cristão. Lisboa: Edições Colibri/Câmara Municipal, 2004.

46 PAIXÃO, António; FARIA, João Carlos; CARVALHO, António Rafael - "O Castelo de Alcácer do Sal...”.
}

Medievalista online № 17। Jane iro - Junho 2015 (C) IEM - Instituto de Estudo s Me die va is 14 www2.fc sh.unl.pt/ie m/me die valista 


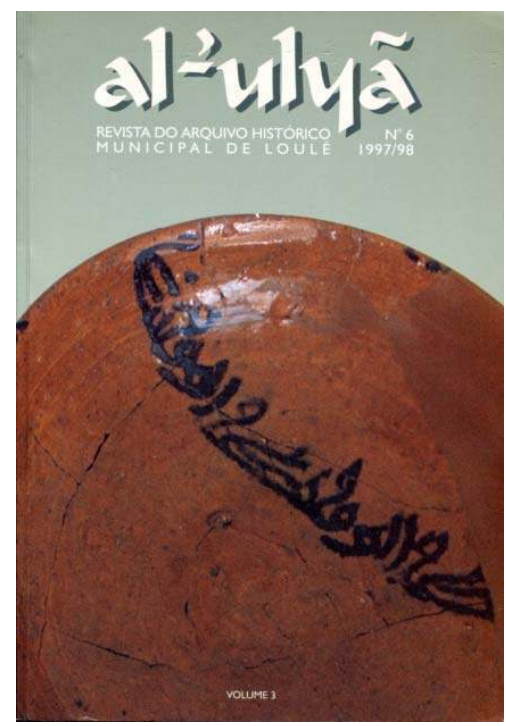

Figura 7. Capa do volume 3 da obra O Algarve Oriental durante a ocupação islâmica. Povoamento rural e recintos fortificados (1998), de Helena Catarino.

Na região de Mértola, a experiência de Alcaria Longa ${ }^{47}$ e a intervenção na fortificação omíada de Mesas do Castelinho ${ }^{48}$, forneceram também o seu contributo neste âmbito. Mais a norte, na península da Arrábida, as escavações na alcaria do Alto da Queimada (Palmela), iniciadas em 1996, revelaram cerâmicas de tradição autóctone e dos períodos omíada e califal, importantes para o entendimento dos espaços domésticos campesinos $^{49}$.

Ainda no que respeita à apresentação, discussão e publicação de estudos, saliente-se a nova dinâmica que surgiu, no coração das Beiras, em torno da cerâmica medieval e pósmedieval: as jornadas de Tondela. O primeiro evento teve lugar em 1992, com publicação das actas três anos depois ${ }^{50}$, altura em que se realizam as segundas jornadas,

\footnotetext{
${ }^{47}$ BOONE, James L. - "The third season of the excavations at Alcaria Longa". in Arqueologia Medieval. Porto. n. 2 (1993), pp. 111-126.

${ }^{48}$ FABIÃO, Carlos; GUERRA, Amílcar - "Uma fortificação Omíada em Mesas do Castelinho...".

${ }^{49}$ FERNANDES, Isabel Cristina; CARVALHO, António Rafael - "Elementos para o estudo da ruralidade muçulmana na região de Palmela". in Actas del II Congreso de Arqueología Peninsular. Zamora.1996. Zamora: 1999, pp. 517-526; FERNANDES, Isabel Cristina F. - O Castelo de Palmela ...

${ }^{50}$ ABRAÇOS, Helder; DIOGO, João Manuel (eds.) - Actas das 1. ${ }^{a s}$ Jornadas de Cerâmica Medieval e Pós-Medieval. Métodos e resultados para o seu estudo. Tondela: Câmara Municipal, 1995.
} 
A propósito da investigação sobre cerâmica islâmica em Portugal • Isabel Inácio, Constança dos Santos, Catarina Coelho, Marco Liberato, Ana Sofia Gomes, Jacinta Bugalhão, Helena Catarino, Sandra Cavaco, Jaquelina Covaneiro, Isabel Cristina Fernandes, Susana Gómez, Maria José Gonçalves

editadas em $1998^{51}$. No que toca à cerâmica islâmica, a participação nas primeiras jornadas restringiu-se aos sítios então com maior impacto arqueológico: Mértola e Silves. Rosa Varela Gomes apresenta, nestas jornadas, um ponto de situação sobre o estudo de cerâmicas islâmicas do sul de Portugal ${ }^{52}$. Nas jornadas de 1995 alargou-se o espaço geográfico de proveniência das peças em análise (Évora, Castro da Cola, Olhão) mas, percentualmente, continuaram a predominar as abordagens à cerâmica do universo cristão medieval e moderno. Sublinhe-se que dois dos artigos se dedicaram à análise de cerâmicas decoradas a verde e manganés, um de Susana Gómez ${ }^{53}$ e outro de Mário Varela Gomes ${ }^{54}$, também evidenciadas por Félix Teichner ${ }^{55}$ para Évora, a par de decorações de corda seca. Igualmente em 1995, o VI Congresso A Cerâmica Medieval no Mediterrâneo, realizado em Aix-en-Provence, contou com contributos portugueses sobre cerâmica islâmica de Mértola ${ }^{56}$ e de Palmela ${ }^{57}$.

No que respeita à apresentação pública, na exposição Lisboa Subterrânea, no Museu Nacional de Arqueologia, o espólio de época islâmica teve já o seu lugar, evidenciado no catálogo por Cláudio Torres ${ }^{58}$ e reafirmado depois em obras de grande divulgação como a História da Arte Portuguesa ${ }^{59}$ e O legado islâmico em Portugal ${ }^{60}$.

\footnotetext{
${ }^{51}$ ABRAÇOS, Helder; DIOGO, João Manuel (eds.) - Actas das 2. ${ }^{a s}$ Jornadas de Cerâmica Medieval e Pós-Medieval. Tondela: Câmara Municipal, 1998.

52 GOMES, Rosa Varela - "Cerâmicas medievais do Sul de Portugal. Qual o Estado da Questão?”. in Actas das 1. ${ }^{\text {as }}$ Jornadas de Cerâmica Medieval e Pós-Medieval. Métodos e resultados para o seu estudo. Tondela. 28 a 31 de Outubro de 1992. Tondela. Câmara Municipal, 1995, pp. 287-296.
}

${ }^{53}$ GÓMEZ MARTÍNEZ, Susana - "Cerâmica de verde e manganês do Castro da Cola". in Actas das 2. ${ }^{a s}$ Jornadas de Cerâmica Medieval e Pós-Medieval. Métodos e resultados para o seu estudo. Tondela. 22 a 25 de Março de 1995. Tondela: Câmara Municipal, 1998, pp. 57-65.

${ }^{54}$ GOMES, Mário Varela - "Cerâmicas islâmicas do poço da Hortinhola (Moncarapacho, Olhão)". in

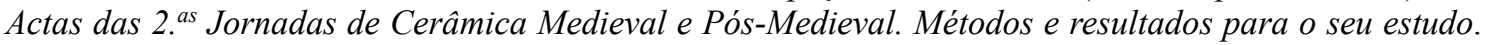
Tondela. 22 a 25 de Março de 1995. Tondela: Câmara Municipal, 1998, pp. 33-41.

55 TEICHNER, Félix - "A ocupação do centro da cidade de Évora da época romana à contemporânea. Primeiros resultados da intervenção do Instituo Arqueológico Alemão". in Actas das 2. ${ }^{\text {as }}$ Jornadas de Cerâmica Medieval e Pós-Medieval. Métodos e resultados para o seu estudo. Tondela. 22 a 25 de Março de 1995. Tondela: Câmara Municipal de Tondela, 1998, pp. 17-31.

${ }^{56}$ GÓMEZ MARTíNEZ, Susana - "Cerámica decorada islámica de Mértola - Portugal (s. IX-XIII)". in Actes du VI Congrès La céramique médiévale en Méditerranée. Aix-en-Provence: Narration Éditions, 1997, pp. 311-325.

${ }^{57}$ FERNANDES, Isabel Cristina; CARVALHO, António Rafael - "Cerâmicas muçulmanas...".

${ }^{58}$ TORRES, Cláudio - "Lisboa muçulmana. Um espaço urbano e o seu território". in Lisboa Subterrânea. Lisboa, Instituto Português de Museus, 1994, pp. 80-85.

${ }^{59}$ De que destacamos o texto de Cláudio Torres e Santiago Macias aí integrado: TORRES, Cláudio; MACIAS, Santiago - "A Arte Islâmica no Ocidente Andaluz". in PEREIRA, Paulo, História da Arte Portuguesa. Vol. 1. Lisboa: Círculo de Leitores, 1995, pp. 150-177. 


\section{De 1998 à actualidade: entre $O$ Portugal Islâmico. Os últimos sinais do Mediterrâneo e o X Congresso Internacional sobre a Cerâmica Medieval no Mediterrâneo}

A exposição O Portugal Islâmico. Os últimos sinais do Mediterrâneo (1998), patente no Museu Nacional de Arqueologia, teve uma importância singular na divulgação perante o público em geral, devido à sua abrangência territorial e número de visitantes. É de lamentar que o catálogo ${ }^{61}$, rapidamente esgotado, não tenha sido reeditado. A esta exposição seguiram-se outras, com importantes conteúdos em cerâmica islâmica - por exemplo, Palácio Almóada da Alcáçova de Silves - Silves, 200162; De Scallabis a Santarém - Santarém, 2002 ${ }^{63}$; Tavira. Território e poder - Tavira, $2003^{64}$; Ribāt da Arrifana. Cultura material e espiritualidade, Aljezur, 200765; Palmela Arqueológica. Espaços, Vivências, Poderes, Palmela, 200866; Os signos do quotidiano, Mértola, $2011^{67}$ - e a inauguração de vários museus monográficos com colecções islâmicas (Mértola em 2001 e Tavira em 2012), sempre acompanhados dos respectivos catálogos.

60 TORRES, Cláudio; MACIAS, Santiago (dir.) - O legado islâmico em Portugal. Lisboa: Círculo de Leitores, 1998.

${ }^{61}$ TORRES, Cláudio; MACIAS, Santiago (dir.) - Portugal Islâmico. Os últimos sinais do Mediterrâneo. Lisboa: Museu Nacional de Arqueologia, 1998a.

${ }^{62}$ GOMES, Rosa Varela; GOMES, Mário Varela - Palácio Almóada da Alcáçova de Silves. Catálogo da Exposição. Lisboa: Museu Nacional de Arqueologia, 2001.

${ }^{63}$ ARRUDA, Ana Margarida; ALMEIDA, Maria José; VIEGAS, Catarina - De Scallabis a Santarém. Lisboa: Instituto Português de Museus, 2002.

${ }^{64}$ MAIA, Maria et alii - Tavira. Território e poder. Catálogo da Exposição. Lisboa: Museu Nacional de Arqueologia/Câmara Municipal de Tavira, 2003.

65 GOMES, Rosa Varela; GOMES, Mário Varela (ed.) - Ribāt da Arrifana. Cultura material e espiritualidade. Aljezur: Associação de Defesa do Património Histórico e Arqueológico de Aljezur/Município de Aljezur, 2007.

66 FERNANDES, Isabel Cristina; SANTOS, Michelle Teixeira (coord.) - Palmela Arqueológica: Espaços, Vivências, Poderes. Roteiro da Exposição. Palmela: Município de Palmela, 2008.

${ }^{67}$ GÓMEZ MARTÍNEZ, Susana (coord.) - Os Signos do Quotidiano: Gestos, Marcas e Símbolos no alÂndalus. Catálogo da Exposição. Mértola: Campo Arqueológico de Mértola, 2011. 
A propósito da investigação sobre cerâmica islâmica em Portugal • Isabel Inácio, Constança dos Santos, Catarina Coelho, Marco Liberato, Ana Sofia Gomes, Jacinta Bugalhão, Helena Catarino, Sandra Cavaco, Jaquelina Covaneiro, Isabel Cristina Fernandes, Susana Gómez, Maria José Gonçalves

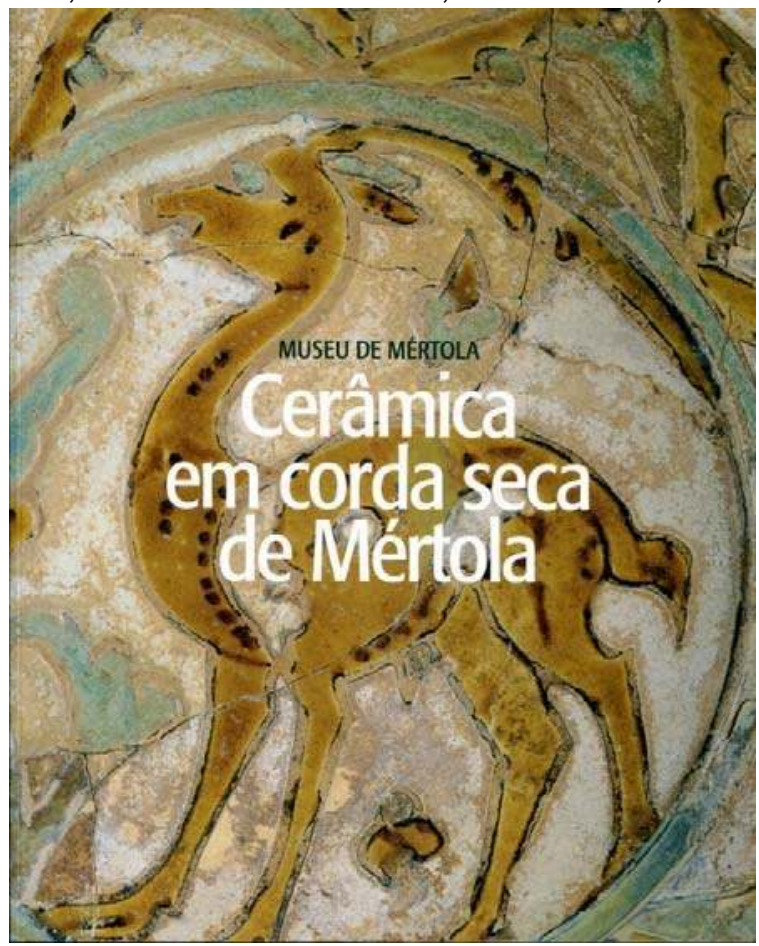

Figura 8. Capa do catálogo Cerâmica em Corda Seca de Mértola (2002), textos de Susana Gómez e Claire Déléry, catálogo de Susana Gómez.

Não é de somenos importância a presença de peças portuguesas em importantes exposições internacionais como Les Andalousies de Damas à Cordoue (Paris, 2000), El esplendor de los Omeyas cordobeses (Madinat al-Zahra, 2001), Los Jarrones de la Alhambra. Simbología y poder (Alhambra de Granada, 2007) ou Lusa: a matriz portuguesa (Brasília-São Paulo, 2008), esta última visitada por mais de um milhão de pessoas. 
A propósito da investigação sobre cerâmica islâmica em Portugal • Isabel Inácio, Constança dos Santos, Catarina Coelho, Marco Liberato, Ana Sofia Gomes, Jacinta Bugalhão, Helena Catarino, Sandra Cavaco, Jaquelina Covaneiro, Isabel Cristina Fernandes, Susana Gómez, Maria José Gonçalves

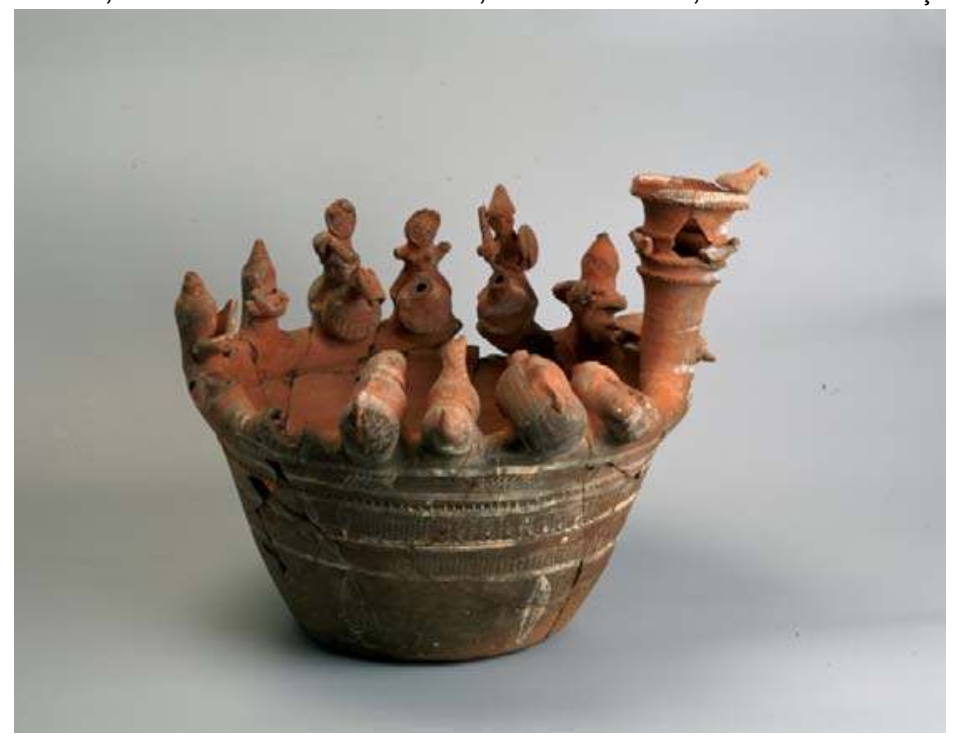

Figura 9. Vaso de Tavira, proveniente das escavações do BNU dirigidas por Maria e Manuel Maia; peça exposta em várias exposições nacionais e internacionais.

Para além do efeito benéfico das actividades expositivas e museográficas, foi de grande importância a realização de várias séries de congressos que se transformaram num eficaz veículo de difusão nesta área, com mais de 100 artigos publicados. A continuidade dada às jornadas de Tondela serviu, por um lado, de meio de publicação, mas sobretudo foi um foro de debate fundamental ${ }^{68}$. De referir ainda a enorme importância destes encontros no âmbito da cerâmica moderna, a que nem sempre a arqueologia deu a devida atenção.

Desde 2001, os Encontros de Arqueologia do Algarve, organizados pela Câmara Municipal de Silves (publicados na $X e l b$ ), têm sido um palco privilegiado, não só para a arqueologia do Algarve mas de todo o país. Neles, os conteúdos islâmicos tiveram sempre uma ampla representação, sendo de salientar o $6 .^{\circ}$ Encontro realizado em 2008 , com carácter monográfico: $O$ Gharb no al-Andalus: sínteses e perspectivas de estudo ${ }^{69}$. As actas publicadas através da revista Xelb são de vital importância para perceber a

\footnotetext{
${ }^{68}$ ABRAÇOS, Helder; DIOGO, João Manuel (eds.) - Actas das 3. as Jornadas de Cerâmica Medieval e Pós-Medieval. Tondela: Câmara Municipal, 2004; DIOGO, João Manuel (ed.) - Actas das $4^{\text {as }}$ Jornadas de Cerâmica Medieval e Pós-Medieval: métodos e resultados para o seu estudo. Tondela: Câmara Municipal, 2008.

69 GONÇALVES, Maria José (ed.) - O Gharb no al-Andalus: sínteses e perspectivas de estudo. Homenagem a José Luís de Matos (Xelb, 9). Silves, 2009.
} 
A propósito da investigação sobre cerâmica islâmica em Portugal • Isabel Inácio, Constança dos Santos, Catarina Coelho, Marco Liberato, Ana Sofia Gomes, Jacinta Bugalhão, Helena Catarino, Sandra Cavaco, Jaquelina Covaneiro, Isabel Cristina Fernandes, Susana Gómez, Maria José Gonçalves

evolução da investigação arqueológica do país, especialmente por ser, em muitos casos, o veículo de publicação escolhido pela arqueologia preventiva e empresarial.

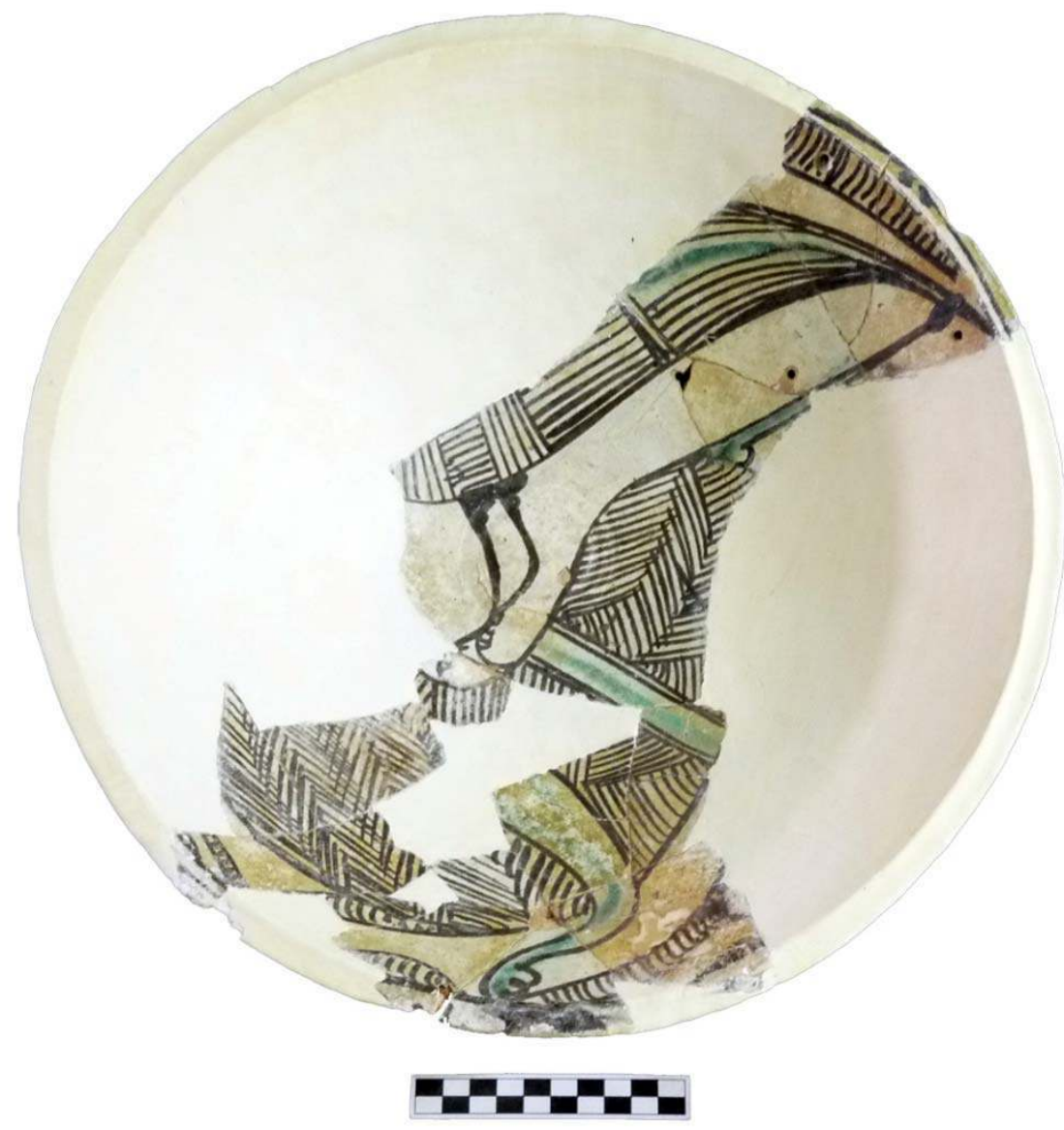

Figura 10. Tigela em verde e manganês de finais do século XI ou primeira metade do XII, proveniente das escavações da Biblioteca Municipal de Silves dirigidas por Maria José Gonçalves.

No âmbito internacional, a participação nos congressos da Cerâmica Medieval no Mediterrâneo - Tessalónica, 199970; Ciudad Real, 2006 ${ }^{71}$; Veneza, $2009^{72}$ - tem mantido um nível razoável de estudos sobre a cerâmica do Ġarb al-Andalus, com uma grande repercussão a nível internacional.

\footnotetext{
${ }^{70}$ BAKIRTZIS, Charalambos (ed.) - Actes du VIIe Congrès Internacional sur la Céramique Médiévale en Méditerranée. Atenas: Ministère de la Culture/Caísse des Recettes Archéologiques, 2003.

${ }^{71}$ ZOZAYA STABEL-HANSEN, Juan et allí (eds.) - Actas del VIII Congreso Internacional de Cerámica Medieval en el Mediterráneo. 2 Tomos. Ciudad Real: Asociación Española de Arqueología Medieval, 2009.

72 GELICHI, Sauro (ed.) - Atti del IX Congresso Internazionale sulla Ceramica Medievale nel Mediterraneo. Venezia: Edizioni All'Insegna del Giglio, 2012.
} 
A propósito da investigação sobre cerâmica islâmica em Portugal • Isabel Inácio, Constança dos Santos, Catarina Coelho, Marco Liberato, Ana Sofia Gomes, Jacinta Bugalhão, Helena Catarino, Sandra Cavaco, Jaquelina Covaneiro, Isabel Cristina Fernandes, Susana Gómez, Maria José Gonçalves

A estas séries de congressos podemos acrescentar um elevado número de encontros científicos monográficos entre os quais destacamos Mil anos de fortificações na Península Ibérica e no Magreb. Actas do Simpósio Internacional sobre Castelos $(2000)^{73}$, Muçulmanos e cristãos entre o Tejo e o Douro (2003) ${ }^{74}$, Al-Andalus espaço de Mudança $(2005)^{75}$, etc.

Quantitativamente, a cerâmica do Ġarb al-Andalus teve menor representação nos Congressos de Arqueologia Peninsular (Zamora, 1996; Vila Real de Trás-os-Montes, 1999; Faro, 2004) e nos Encontros de Arqueologia do Sudoeste Peninsular (Faro, 1996; Aljustrel, 2006; Aracena, 2008; Almodôvar, 2010; e Villafranca de los Barros, 2012).

Também foi exponencial o aumento de trabalhos académicos sobre o Ġarb al-Andalus nos quais a cerâmica assume um aspecto fundamental. À já mencionada tese de doutoramento de Helena Catarino (na Universidade de Coimbra em 1997), vem juntarse a de Rosa Varela Gomes, defendida na Universidade Nova de Lisboa, em 1998, que veio a ser publicada paulatinamente na série Trabalhos de Arqueologia $^{76}$. Posteriormente foi defendida a tese de Susana Gómez Martínez (Universidade Complutense de Madrid, 2004) ${ }^{77}$ sobre produção e comércio de cerâmica islâmica em Mértola. Os materiais do Ġarb al-Andalus mereceram uma atenção especial na tese de Claire Déléry sobre as cerâmicas de corda seca (Universidade de Toulouse, 2006).

\footnotetext{
${ }^{73}$ Publicado em FERNANDES, Isabel Cristina F. (ed.) - Mil Anos de Fortificações na Península Ibérica e no Magreb (500-1500). Palmela: Ed. Colibri/Câmara Municipal de Palmela, 2002.

${ }^{74}$ Publicado em BARROCA, Mário J.; FERNANDES, Isabel Cristina (eds.) - Muçulmanos e cristãos entre o Tejo e o Douro (Sécs. VIII a XIII). Palmela: Câmara Municipal/Faculdade de Letras da Universidade do Porto, 2005.

75 Publicado em GÓMEZ MARTÍNEZ, Susana (ed.) - Al-Ândalus espaço de mudança. Balanço de 25 anos de história e arqueologia medievais. Seminário de Homenagem a Juan Zozaya Stabel-Hansen. Mértola: Campo Arqueológico de Mértola, 2006.

${ }^{76}$ GOMES, Rosa Varela - Silves (Xelb), uma cidade do Gharb al-Andalus: território e cultura (Trabalhos de Arqueologia, 23). Lisboa: Instituto Português de Arqueologia, 2002; idem - Silves (Xelb), uma cidade do Gharb al-Andalus: a Alcáçova (Trabalhos de Arqueologia, 35). Lisboa: Instituto Português de Arqueologia, 2004; idem - Silves (Xelb), uma cidade do Gharb al-Andalus: o núcleo urbano (Trabalhos de Arqueologia, 44). Lisboa: Instituto Português de Arqueologia, 2006; idem - Silves (Xelb), uma cidade do Gharb al-Andalus: a zona da Arrochela (Trabalhos de Arqueologia, 53). Lisboa: IGESPAR, 2011.

77 Publicada em 2006: GÓMEZ MARTÍNEZ, Susana - Cerámica Islámica de Mértola: producción y comercio. Madrid: Servicio de Publicaciones de la Universidad Complutense de Madrid, 2006.
}

Medievalista online № 17। Ja ne iro - Junho 2015 (C) $\mathbb{E M}$ - Instituto de Estudos Me die va is 21 www2.fc sh.unl.pt/ ie m/me die va lista 
A propósito da investigação sobre cerâmica islâmica em Portugal • Isabel Inácio, Constança dos Santos, Catarina Coelho, Marco Liberato, Ana Sofia Gomes, Jacinta Bugalhão, Helena Catarino, Sandra Cavaco, Jaquelina Covaneiro, Isabel Cristina Fernandes, Susana Gómez, Maria José Gonçalves

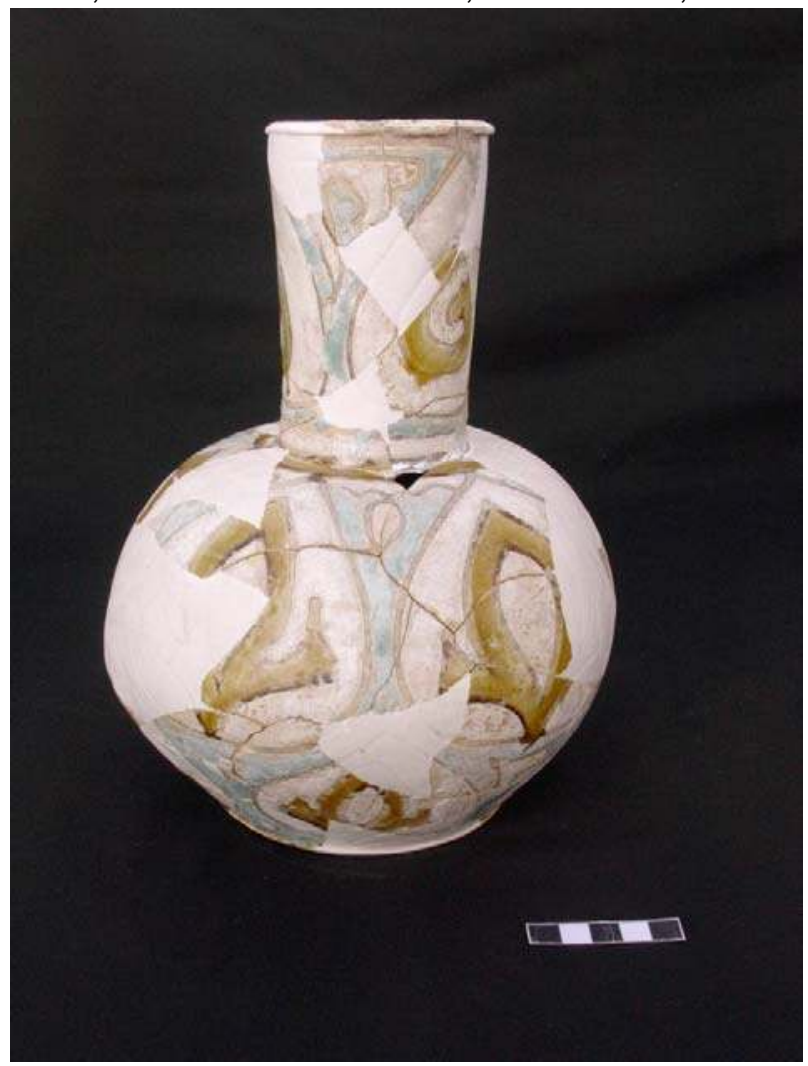

Figura 11. Bilha em corda seca total do século XII, proveniente das escavações da Rua do Sembrano de Beja dirigidas por Susana Correia.

Refira-se ainda, no que respeita aos estudos islâmicos em geral, as teses de doutoramento de Santiago Macias (Universidade de Lyon 2, 2005) ${ }^{78}$, também sobre Mértola e o seu território, e a de Fernando Branco Correia, defendida em 2010, na Universidade de Évora, sob o tema Fortificação, guerra e poderes no Ġarb al-Andalus (dos inícios da islamização ao domínio norte-africano).

Destaca-se ainda cerca de vinte dissertações de mestrado, umas exclusivamente sobre cerâmicas - Rocío Álvaro (2001) $)^{79}$, Nádia Torres $(2004)^{80}$, Carlos Silva (2008), Inês Simão (2008), Maria Mulize Ferreira (2009), Liliana Serrano (2011), Marta Silva (2011), Marco Liberato (2012), Vanessa Filipe (2012), Patrícia Rodrigues (2012), Sarah

\footnotetext{
${ }^{78}$ Publicada em 2006: MACIAS, Santiago - Mértola - O último porto do Mediterrâneo. Mértola: Campo Arqueológico de Mértola. 3 vol, 2006.

79 Publicada em 2011: ÁlVARO SÁNCHEZ, Rocío - Cacela (Algarbe-Portugal) en el siglo XIII: Sociedad y Cultura Material (BAR International Series, 2290). Oxford: Archaeopress, 2011.

${ }^{80}$ Publicada em 2011: TORRES, Nádia Ferreira - O desenho na cerâmica islâmica de Mértola. Mértola: Campo Arqueológico de Mértola, 2011.
} 
A propósito da investigação sobre cerâmica islâmica em Portugal • Isabel Inácio, Constança dos Santos, Catarina Coelho, Marco Liberato, Ana Sofia Gomes, Jacinta Bugalhão, Helena Catarino, Sandra Cavaco, Jaquelina Covaneiro, Isabel Cristina Fernandes, Susana Gómez, Maria José Gonçalves

Henry (2012), Helena Casmarrinha (2013) e João Araújo, (2014) -, e outras, onde estas produções têm papel importante na contextualização e compreensão dos monumentos e sítios estudados - Isabel Cristina Fernandes (2001) ${ }^{81}$, Maria José Gonçalves (2008), Sandra Cavaco (2011) e Luís Ribeiro Gonçalves (2012).

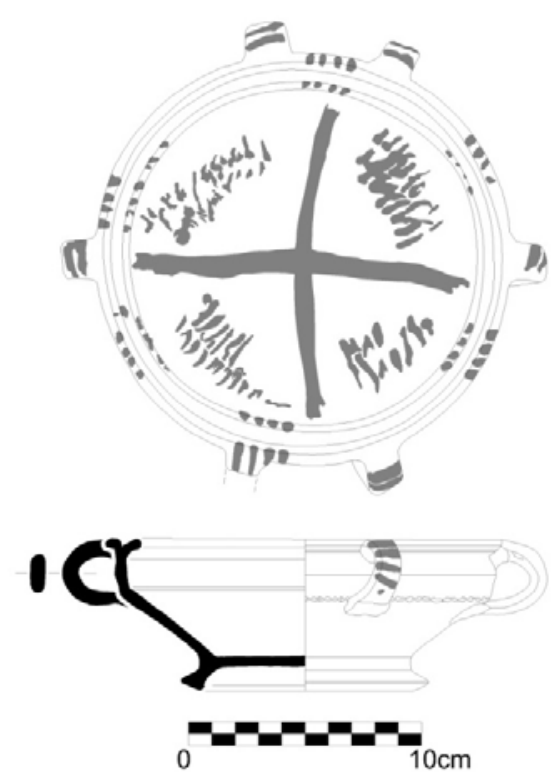

Figura 12. Tigela pintada a branco da primeira metade do século XIII de tradição islâmica proveniente de Santarém $^{82}$.

A partir da data da exposição do Portugal Islâmico assistimos a um incremento significativo de publicações com referências a cerâmica islâmica: cerca de 3/4 das referências são posteriores a 1998. Na impossibilidade de descrever pormenorizadamente os quase 300 títulos referenciados, para uma consulta bibliográfica mais exaustiva, remetemos para a bibliografia deste artigo, bem como para as actas do encontro $O \dot{G}$ arb al-Andalus. Problemáticas e novos contributos em torno da cerâmica, que teve lugar em Mértola no ano de $2009^{83}$.

\footnotetext{
${ }^{81}$ Publicada em FERNANDES, Isabel Cristina F. - O Castelo de Palmela ...

${ }^{82}$ LIBERATO, Marco António Antunes - A cerâmica pintada a branco na Santarém Medieval: uma abordagem diacrónica séculos XI a XVI. Tese de mestrado em Arqueologia, Universidade de Lisboa, Faculdade de Letras, 2012. http://hdl.handle.net/10451/6023.

${ }^{83}$ MACIAS, Santiago; GÓMEZ MARTÍNEZ, Susana (dir.) - O Gharb Al-Ândalus. Problemáticas e novos contributos em torno da cerâmica, Mértola, 2009. Porto: Edições Afrontamento (Arqueologia Medieval, 12), 2012.
} 
A propósito da investigação sobre cerâmica islâmica em Portugal • Isabel Inácio, Constança dos Santos, Catarina Coelho, Marco Liberato, Ana Sofia Gomes, Jacinta Bugalhão, Helena Catarino, Sandra Cavaco, Jaquelina Covaneiro, Isabel Cristina Fernandes, Susana Gómez, Maria José Gonçalves

Nos últimos anos, grande parte da investigação desenvolvida residiu na enorme quantidade de informação trazida à luz pela explosão da arqueologia preventiva. Mesmo que muita dessa informação se mantenha ainda inédita, devido aos constrangimentos e problemas estruturais da arqueologia portuguesa, agravados pela incipiência da actividade de investigação, são meritórias as intervenções publicadas sobre sítios islâmicos, embora a análise dos materiais costume ser sempre fugaz e carente do pormenor que desejaríamos. É de destacar o contributo decisivo que este tipo de intervenções teve no conhecimento de algumas cidades, em muitos casos graças ao papel decisivo das equipas municipais de arqueologia. Destacaremos, entre os casos mais bem-sucedidos, Coimbra e Santarém ${ }^{84}$, Lisboa ${ }^{85}$, Faro e Loulé ${ }^{86}$, Silves ${ }^{87}$ e Tavira $^{88}$.

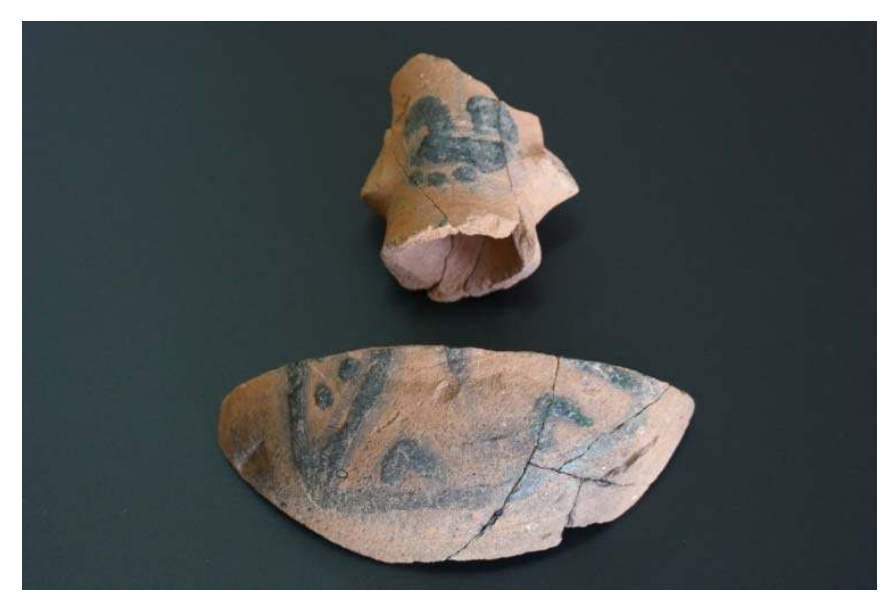

Figura 13. Fragmento de bilha em corda seca parcial proveniente das escavações no Colégio da Trindade (Coimbra), sob direcção de Helena Catarino, Sónia Filipe e Vera Santos. ${ }^{89}$

\footnotetext{
${ }^{84}$ Uma síntese de ambas em CATARINO, Helena; SANTOS, Constança dos - "A cerâmica Islâmica da Marca Inferior em território português". in Arqueologia Medieval. Porto. n. 12 (2012), pp. 7-14.

${ }^{85}$ Uma síntese em BUGALHÃO, Jacinta; FERNANDES, Isabel Cristina - "A cerâmica Islâmica nas regiões de Lisboa e Setúbal". in Arqueologia Medieval. Porto. n. ${ }^{\circ} 12$ (2012), pp. 71-89.

${ }^{86}$ Uma síntese de ambas em CATARINO, Helena; INÁCIO, Isabel - "O Algarve Central". in Arqueologia Medieval. Porto. n. ${ }^{\circ} 12$ ( 2012), pp. 155-161.

${ }^{87}$ Uma síntese em GONÇALVES, Maria José - "O Barlavento Algarvio". in Arqueologia Medieval. Porto. n. ${ }^{\circ} 12$ (2012), pp. 163-168.

${ }^{88}$ Uma síntese em CATARINO, Helena; COVANEIRO, Jaquelina; CAVACO, Sandra - "O Sotavento Algarvio". in Arqueologia Medieval. Porto. n. ${ }^{\circ} 12$ (2012), pp. 147-154.

${ }^{89}$ CATARINO, Helena; FILIPE, Sónia e SANTOS, Constança - "Coimbra islâmica: uma aproximação aos materiais cerâmicos". in Xelb 9. Actas do $6^{\circ}$ Encontro de Arqueologia do Algarve. O Gharb no alAndalus; sintese e perspectivas de estudo. Homenagem a José Luís de Matos (Silves, 2008). Silves: Museu Municipal de Arqueologia - Câmara Municipal de Silves, 2009, pp. 333-376.
} 
A propósito da investigação sobre cerâmica islâmica em Portugal • Isabel Inácio, Constança dos Santos, Catarina Coelho, Marco Liberato, Ana Sofia Gomes, Jacinta Bugalhão, Helena Catarino, Sandra Cavaco, Jaquelina Covaneiro, Isabel Cristina Fernandes, Susana Gómez, Maria José Gonçalves

Em âmbito rural destacaremos os resultados obtidos nos territórios dos estuários de Tejo e $\operatorname{Sado}^{90}$ e nas áreas afectadas pelo empreendimento do Alqueva ${ }^{91}$.

É neste período que se desenvolvem os primeiros trabalhos arqueométricos, em Mértola $^{92}$ e, com bons resultados, em Lisboa ${ }^{93}$.

Contudo, são ainda poucos os projectos de investigação sistemática para a cerâmica do Ġarb al-Andalus. Destacam-se o projecto POILIX, sobre a produção e consumo de cerâmicas islâmicas do NARC/BCP e Mandarim Chinês, entre 1997 e $2006^{94}$ e o projecto Garb. Sitios Islâmicos do Sul Peninsular ${ }^{95}$. Esta escassez de projectos de investigação sistemática de conjunto tem provocado uma acentuada falta de estudos de

${ }^{90}$ Uma síntese em BUGALHÃO, Jacinta; FERNANDES, Isabel Cristina - "A cerâmica Islâmica nas regiões...".

${ }^{91}$ GÓMEZ MARTÍNEZ, Susana; et alii - "Evidências materiais da ocupação islâmica da margem direita do Guadiana". in Xelb. Silves. n. 9 (2009), pp. 685-694; GÓMEZ MARTÍNEZ, Susana; GRANGÉ, Mathieu; LOPES, Gonçalo - "A cerâmica islâmica no Alentejo". in Arqueologia Medieval. Porto. n. ${ }^{\circ} 12$ (2012), pp. 109-119; MARQUES, João et alii - "Cerâmica e povoamento rural medieval no troço médioinferior do vale do Guadiana (Alentejo, Portugal)". in Atti del IX Congresso Internazionale sulla Ceramica Medievale nel Mediterraneo. Venezia, 2009. Venezia; Edizioni All'Insegna del Giglio, 2012, pp. 442-448; SANTOS, Heloísa Valente dos; ABRANCHES, Paula Barreira - "Ocupações do período Medieval e Moderno nos concelhos de Moura e Mourão". In Al-Madan. Almada. 2. ${ }^{a}$ série, n. 11 (2002), pp. 152-157.

92 BRIDGMAN, Rebecca - "Re-examining Almohad Economies in South-Western Al-Andalus through Petrological Analysis of Archaeological Ceramics". in. ANDERSON, Glaire; ROSSER-OWEN, Mariam (eds.) - Revisiting Al-Andalus: Perspectives on the Material Culture of Islamic Iberia and Beyond. The Medieval and Modern Iberian World. Leiden: Brill, 2007, pp. 143-165; DÉLÉRY, Claire - Dynamiques économiques sociales et cultureles d'al-Andalus à partir d'une étude de la céramique de cuerda seca (seconde moitié du Xesiècle-première moitié du XIIIe siècle). Tese de doutoramento. Toulouse. 7 Vols., 2006 ; DÉLÉRY, Claire; CHAPOULIE, R.; DELAGUE, D. - "Contribution à l'étude de l'évolution technologique et du commerce des céramiques de cuerda seca en al-Andalus $\left(\mathrm{X}^{\circ}-\mathrm{XII}{ }^{\circ} \mathrm{S}\right)$ ". in Actas del VIII Congreso internacional de cerámica medieval en el Mediterráneo. Ciudad Real: Asociación española de arqueología medieval, 2009, pp. 571-597; GÓMEZ MARTÍNEZ, Susana - Cerámica Islámica de Mértola...

${ }^{93}$ DIAS, Maria Isabel; PRUDÊNCIO, Maria Isabel; GOUVEIA, Maria Ângela - "Arqueometria de cerâmicas islâmicas das regiões de Lisboa, Santarém e Alcácer do Sal (Portugal): caracterização química e mineralógica". in Garb, Sítios Islâmicos do Sul Peninsular. Lisboa: IPPAR/Junta de Extremadura, 2001, pp. 257-281; DIAS, Maria Isabel et alii - "A produção de cerâmicas no arrabalde ocidental da Lisboa islâmica. Primeiros resultados arqueométricos". in Promontoria Monográfica. Faro. 11 (2008), pp. 157167. DIAS, Maria Isabel et alii - "Tecnologias de produção de cerâmicas pintadas dos séculos XI a XII do Castelo de S. Jorge (Lisboa, Portugal)". in Actas del VIII Congreso Internacional de Cerámica Medieval en el Mediterráneo. Tomo II. Ciudad Real: Asociación Española de Arqueología Medieval, 2009, pp. 963-966.

${ }^{94}$ BUGALHÃO, Jacinta et alii - "Produção e consumo de cerâmica islâmica em Lisboa: conclusões de um projecto de investigação". in Arqueologia Medieval. Porto. n. ${ }^{\circ} 10$ (2008), pp. 113-134.

${ }^{95}$ LACERDA, Manuel; SOROMENHO, Miguel; RAMALHO, Maria Magalhães; LOPES, Carla (eds.) Garb, Sitios Islâmicos do Sul Peninsular. Lisboa: IPPAR/ Junta de Extremadura, 2001. 
A propósito da investigação sobre cerâmica islâmica em Portugal • Isabel Inácio, Constança dos Santos, Catarina Coelho, Marco Liberato, Ana Sofia Gomes, Jacinta Bugalhão, Helena Catarino, Sandra Cavaco, Jaquelina Covaneiro, Isabel Cristina Fernandes, Susana Gómez, Maria José Gonçalves

síntese, razão pela qual surgiu a iniciativa de criação do Grupo de Estudo da Cerâmica Islâmica do Ġarb al-Andalus (CIGA, http://www.camertola.pt/info/ciga). A necessidade de definir a funcionalidade dos objectos, as diferentes realidades produtivas no tempo e no espaço, a distribuição e o comércio inter-regionais, a criação de categorias cronológicas úteis e a elaboração de estudos de síntese são o grande móbil congregador do projecto deste Grupo CIGA.

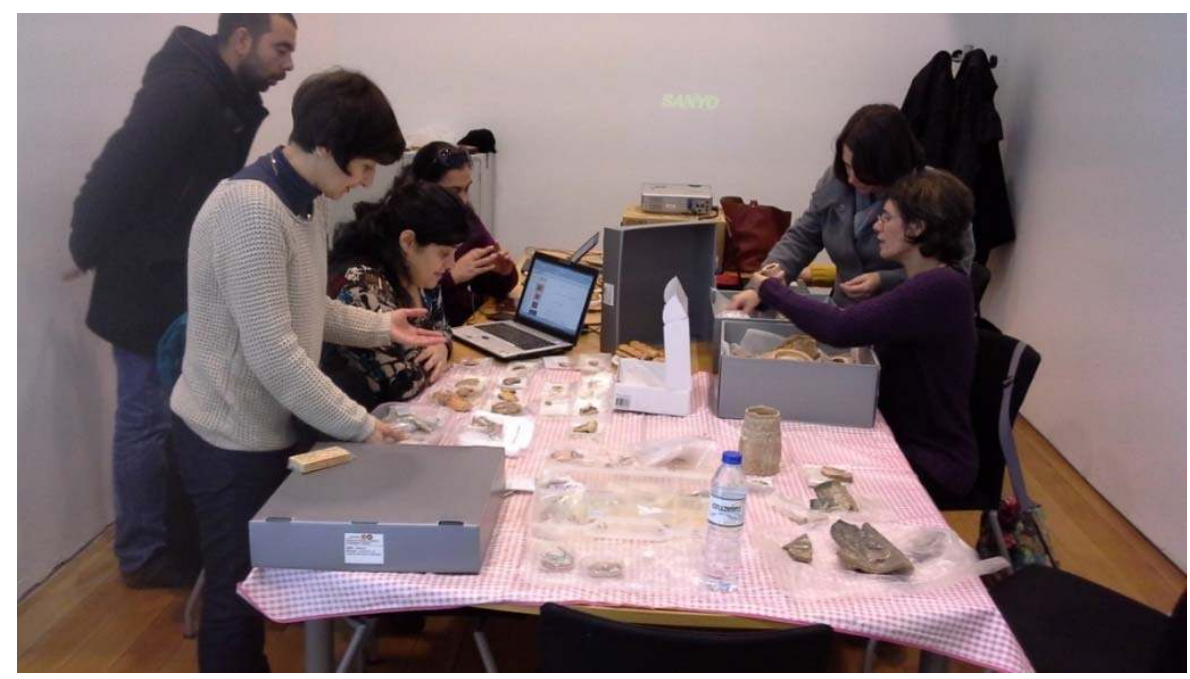

Figura 14. Reunião de trabalho do Grupo de Estudo da Cerâmica Islâmica do Ġarb al-Andalus (CIGA), Palmela, Fevereiro de 2014.

Apesar da falta de financiamento, o projecto promoveu estudos de conjunto ${ }^{96}$, com especial destaque para as abordagens de âmbito regional incluídas nas actas do já referido encontro $O$ Gharb Al-Ândalus. Problemáticas e novos contributos em torno da cerâmica (2012).

A evolução recente da investigação sobre cerâmica islâmica em Portugal espelha-se bem no conjunto de trabalhos apresentados no $X$ Congresso Internacional sobre a Cerâmica Medieval no Mediterrâneo (Silves, 2012). Das 44 comunicações e posters

\footnotetext{
${ }^{96}$ BUGALHÃO, Jacinta et alii - "Projecto de sistematização para a cerâmica islâmica do Gharb alÂndalus". in Xelb. Silves. n. ${ }^{\circ} 10$ (2010), pp. 455-476; CATARINO, Helena et alii - "La céramique islamique du Ġarb al-Andalus: contextes socio-territoriaux et distribution". in Atti del IX Congresso Internazionale sulla Ceramica Medievale nel Mediterraneo. Venezia: Edizioni All'Insegna del Giglio, 2012, pp. 429-441; CAVACO, Sandra et alii - "O Gharb al-Andalus. Problemáticas e novos contributos em torno da cerâmica". in Arqueologia Medieval. Porto. 12 (2012), pp. 5-6; COVANEIRO, Jaquelina; et alii - "Cerâmica islâmica em Portugal...".
} 
A propósito da investigação sobre cerâmica islâmica em Portugal • Isabel Inácio, Constança dos Santos, Catarina Coelho, Marco Liberato, Ana Sofia Gomes, Jacinta Bugalhão, Helena Catarino, Sandra Cavaco, Jaquelina Covaneiro, Isabel Cristina Fernandes, Susana Gómez, Maria José Gonçalves

apresentados sobre Portugal, mais de metade (24) versavam sobre cerâmicas islâmicas. Apenas duas comunicações tinham carácter de síntese e outras duas referiam análises arqueométricas, sendo a esmagadora maioria estudos monográficos que em poucos casos ultrapassavam a estrita análise crono-tipológica.

Será que, a partir deste congresso, podemos esperar um salto qualitativo e quantitativo semelhante ao que aconteceu há 25 anos, após o IV Congresso da Cerâmica Medieval no Mediterrâneo de Lisboa? Obviamente a conjuntura socioeconómica não é nada favorável a que tal aconteça. À inexistência de financiamento público específico para a investigação arqueológica, ao desinvestimento de grande parte dos municípios nesta área, junta-se o esperado decréscimo de financiamento pela FCT no âmbito das ciências sociais e humanas, o que, a confirmar-se, augura maus presságios para a consolidação de uma investigação sistemática em arqueologia medieval em geral e na cerâmica islâmica em particular. Por outro lado, a diminuição do número de intervenções arqueológicas preventivas, decorrente do abrandamento da economia, repercutir-se-á na quantidade de novos achados, situação que se espera venha a ser compensada com o estímulo à realização de trabalhos académicos e com o estudo efectivo dos numerosos contextos exumados nas últimas duas décadas e que permanecem em grande parte inéditos. A divulgação do património, aproveitando fundos estruturais, poderá vir a ser um meio de financiamento para alguma investigação dentro deste domínio.

\section{Conclusões}

Por regra geral, verifica-se uma grande disparidade na qualidade da informação disponível decorrente do reduzido conhecimento da cerâmica islâmica, da dificuldade da maioria dos arqueólogos em reconhecê-la e da falta de uniformização na terminologia e nos critérios de representação gráfica.

Do ponto de vista geográfico as assimetrias são muito fortes, registando-se lacunas relevantes a norte do Tejo, com excepção de Coimbra, Santarém e Lisboa, e grande desequilíbrio entre os territórios rurais e urbanos. No Algarve, a existência de um maior número de estudos não pode ser atribuída exclusivamente a factores históricos relacionados com uma mais duradoura e intensa presença islâmica. 
A propósito da investigação sobre cerâmica islâmica em Portugal • Isabel Inácio, Constança dos Santos, Catarina Coelho, Marco Liberato, Ana Sofia Gomes, Jacinta Bugalhão, Helena Catarino, Sandra Cavaco, Jaquelina Covaneiro, Isabel Cristina Fernandes, Susana Gómez, Maria José Gonçalves

Do ponto de vista cronológico, os períodos finais de ocupação são os mais beneficiados, por evidentes razões estratigráficas: a mudança na cultura material provocada pela conquista cristã foi generalizada e muito mais forte do que as mudanças operadas ao longo dos séculos anteriores, onde os elementos de continuidade foram dominantes, deixando poucas evidências estratigráficas. É no âmbito da seriação crono-tipológica que se enquadra a maior quantidade de trabalhos, embora só em alguns casos signifique um esforço de síntese para um território.

Do ponto de vista da produção, as maiores dificuldades prendem-se com o número diminuto de estruturas oleiras encontradas: apenas foram publicadas as localizadas em Vilamoura $^{97}$, Lisboa ${ }^{98}$ e Mértola $^{99}$. Do ponto de vista da distribuição encontramos dificuldades semelhantes, embora alguns avanços se tenham alcançado relativamente às produções de luxo. A maior parte dos autores centra contudo a sua análise nos aspectos funcionais e contextuais.

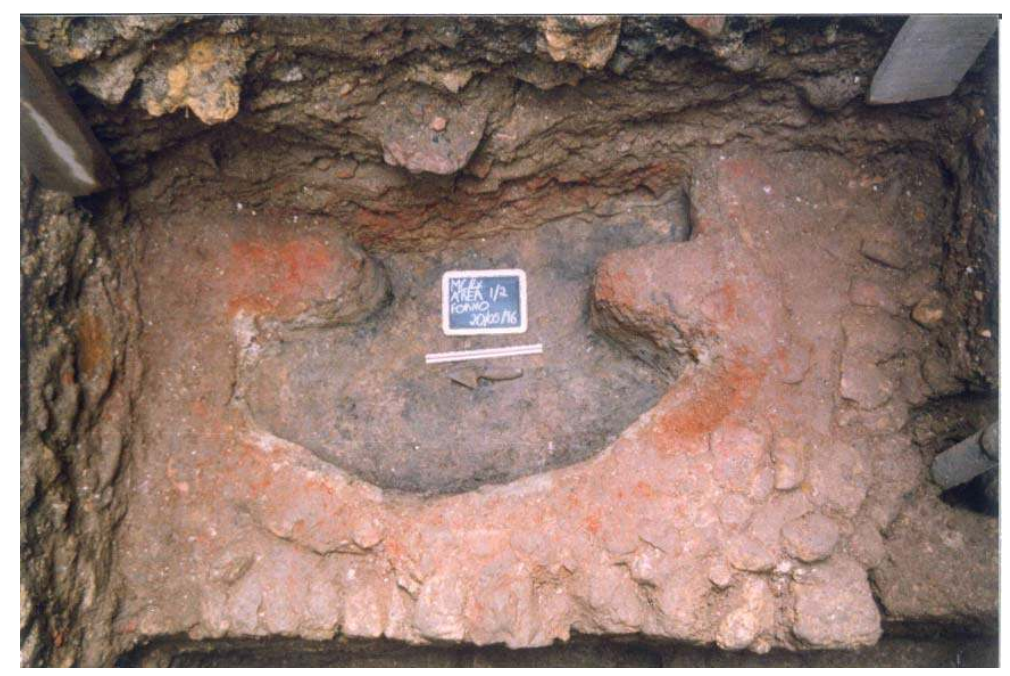

Figura 15. Câmara de combustão do forno de olaria das escavações do Mandarim Chinês, 1996, em Lisboa, dirigidas por Jacinta Bugalhão.

\footnotetext{
${ }^{97}$ MATOS, José Luís de - "Forno cerâmico (Cerro da Vila) - 1982". in Informação Arqueológica. Lisboa. n. ${ }^{\circ} 5$ (1985), p. 77.

${ }^{98}$ BUGALHÃO, Jacinta; GOMES, Ana Sofia; SOUSA, Maria João - "Vestígios de produção oleira islâmica no Núcleo Arqueológico da Rua dos Correeiros, Lisboa". In Arqueologia Medieval. Porto. n. ${ }^{\circ} 8$ (2003), pp. 129-191; BUGALHÃO, Jacinta; SOUSA, Maria João; GOMES, Ana Sofia - "Vestígios de produção oleira no Mandarim Chinês, Lisboa". in Revista Portuguesa de Arqueologia. Lisboa. n. ${ }^{\circ}$ 7:1 (2004), pp. 575-643.

${ }^{99}$ GÓMEZ MARTÍNEZ, Susana - Cerámica Islámica de Mértola ...
} 
A propósito da investigação sobre cerâmica islâmica em Portugal • Isabel Inácio, Constança dos Santos, Catarina Coelho, Marco Liberato, Ana Sofia Gomes, Jacinta Bugalhão, Helena Catarino, Sandra Cavaco, Jaquelina Covaneiro, Isabel Cristina Fernandes, Susana Gómez, Maria José Gonçalves

A abordagem simbólica e iconográfica da cerâmica, sempre arriscada, marcou presença nos primeiros estudos desenvolvidos por José Luís de Matos ${ }^{100}$, de algum modo continuados através do estudo do importante achado do Vaso de Tavira ${ }^{101}$, da tigela com figura sentada, de Palmela ${ }^{102}$ e da já referida exposição Os Signos do Quotidiano $^{103}$.

\section{REFERÊNCIAS BIBLIOGRÁFICAS}

ABRAÇOS, Helder; DIOGO, João Manuel (eds.) - Actas das1. ${ }^{a s}$ Jornadas de Cerâmica Medieval e Pós-Medieval. Métodos e resultados para o seu estudo. Tondela: Câmara Municipal, 1995.

ABRAÇOS, Helder; DIOGO, João Manuel (eds.) - Actas das 2. as Jornadas de Cerâmica Medieval e Pós-Medieval. Tondela: Câmara Municipal, 1998.

ABRAÇOS, Helder; DIOGO, João Manuel (eds.) - Actas das 3. as Jornadas de Cerâmica Medieval e Pós-Medieval. Tondela: Câmara Municipal, 2004.

ÁLVARO SÁNCHEZ, Rocío - Cacela (Algarbe-Portugal) en el siglo XIII: Sociedad y Cultura Material (BAR International Series, 2290). Oxford: Archaeopress, 2011.

ARAÚJO, João Gonçalves - A cerâmica islâmica do castelo de Palmela: análise tipológica e crono-estratigráfica dos materiais da galeria 5. Tese de mestrado em Arqueologia, Universidade de Lisboa, Faculdade de Letras, 2014.

\footnotetext{
${ }^{100}$ MATOS, José Luís de - "Influências orientais na cerâmica muçulmana do Sul de Portugal". in Estudos Orientais. Lisboa. Vol. II (1991), pp. 75-83.

${ }^{101}$ MAIA, Maria - "O Vaso de Tavira e o seu contexto". in Actas do Colóquio Internacional. Portugal, Espanha e Marrocos. O Mediterrâneo e o Atlântico. Faro. 2 a 4 de Novembro de 2000. Faro: Universidade do Algarve/Faculdade de Ciências Humanas e Sociais/Centro de Cultura Árabe, Islâmica e Mediterrânea, 2004, pp. 143-166; idem - Vaso de Tavira. Tavira: Câmara Municipal, 2012; PAULO, Luís Campos - "O simbolismo da purificação. O 'Vaso de Tavira': iconografia e interpretação". in Revista Portuguesa de Arqueologia. Lisboa. n. ${ }^{\circ}$ 10: 1 (2007), pp. 289-316; TORRES, Cláudio - O Vaso de Tavira. Uma proposta de interpretação. Mértola: Campo Arqueológico de Mértola, 2004.

${ }^{102}$ FERNANDES, Isabel Cristina F. - "Uma taça islâmica...”; idem - O Castelo de Palmela...

${ }^{103}$ GÓMEZ MARTÍNEZ, Susana (coord.) - Os Signos do Quotidiano...
}

Medievalista online № 17 I Ja ne iro - Junho 2015 @ $\mathbb{E M}$ - Instituto de Estudos Medievais 29 www2.fc sh.unl.pt/ie m/me die va lista 
A propósito da investigação sobre cerâmica islâmica em Portugal • Isabel Inácio, Constança dos Santos, Catarina Coelho, Marco Liberato, Ana Sofia Gomes, Jacinta Bugalhão, Helena Catarino, Sandra Cavaco, Jaquelina Covaneiro, Isabel Cristina Fernandes, Susana Gómez, Maria José Gonçalves

ARCHIMBAUD, Gabrielle Démians d' (ed.) - Actes du VI Colloque International sur la Céramique Médiévale in Méditerranée. Aix-en-Provence: Narrations Editions, 1997.

ARRUDA, Ana (dir.) - Lisboa Subterrânea. Lisboa: Instituto Português de Museus, 1994.

ARRUDA, Ana Margarida; ALMEIDA, Maria José; VIEGAS, Catarina - De Scallabis $a$ Santarém. Lisboa: Instituto Português de Museus, 2002.

BAKIRTZIS, Charalambos (ed.) - Actes du VIIe Congrès Internacional sur la Céramique Médiévale en Méditerranée. Atenas: Ministère de la Culture/Caisse des Recettes Archéologiques, 2003.

BANHA, Carlos Manuel dos Santos - "As cerâmicas do Alto do Senhor da Boa Morte (Povos): estudo preliminar". in Cira. Vila Franca de Xira. n. 7 (1995-1997), pp. $75-$ 109.

BARROCA, Mário J.; FERNANDES, Isabel Cristina (eds.) - Muçulmanos e cristãos entre o Tejo e o Douro (Sécs. VIII a XIII). Palmela: Câmara Municipal/Faculdade de Letras da Universidade do Porto, 2005.

BARROS, Luís; ESPÍRITO SANTO, Paulo; ANTUNES, L. P. - "Rua da Judiaria (Almada). Notícia preliminar". in Encontro de Arqueologia Urbana (Bracara Augusta, vol. XLV. n. ${ }^{\circ} 97$ (110), 1994, pp. 201-214.

BOONE, James L. - "The third season of the excavations at Alcaria Longa". in Arqueologia Medieval. Porto. n. 2 (1993), pp. 111-126.

BRIDGMAN, Rebecca - "Re-examining Almohad Economies in South-Western AlAndalus through Petrological Analysis of Archaeological Ceramics”. in. ANDERSON, Glaire; ROSSER-OWEN, Mariam (eds.) - Revisiting Al-Andalus: Perspectives on the Material Culture of Islamic Iberia and Beyond. The Medieval and Modern Iberian World. Leiden: Brill, 2007, pp. 143-165.

BUGALHÃO, Jacinta; CATARINO, Helena; CAVACO, Sandra; COVANEIRO, Jaquelina; FERNANDES, Isabel Cristina Fernandes; GOMES, Ana; GÓMEZ MARTÍNEZ, Susana; GONÇALVES, Maria José; GRANGÉ, Mathieu; INÁCIO, 
A propósito da investigação sobre cerâmica islâmica em Portugal • Isabel Inácio, Constança dos Santos, Catarina Coelho, Marco Liberato, Ana Sofia Gomes, Jacinta Bugalhão, Helena Catarino, Sandra Cavaco, Jaquelina Covaneiro, Isabel Cristina Fernandes, Susana Gómez, Maria José Gonçalves

Isabel; LOPES, Gonçalo; SANTOS, Constança - "Projecto de sistematização para a cerâmica islâmica do Gharb al-Ândalus". in Xelb. Silves. n. ${ }^{\circ} 10$ (2010), pp. 455-476.

BUGALHÃO, Jacinta; FERNANDES, Isabel Cristina - "A cerâmica Islâmica nas regiões de Lisboa e Setúbal”. in Arqueologia Medieval. Porto. n. ${ }^{\circ} 12$ (2012), pp. 7189.

BUGALHÃO, Jacinta; FOLGADO, Deolinda - "O arrabalde ocidental da Lisboa islâmica: urbanismo e produção oleira”. in Arqueologia Medieval. Porto. n. 7 (2001), pp. 111-145.

BUGALHÃO, Jacinta; GOMES, Ana Sofia; SOUSA, Maria João - "Vestígios de produção oleira islâmica no Núcleo Arqueológico da Rua dos Correeiros, Lisboa". in Arqueologia Medieval. Porto. n. ${ }^{\circ} 8$ (2003), pp. 129-191.

BUGALHÃO, Jacinta; GOMES, Ana Sofia; SOUSA, Maria João; FOLGADO, Deolinda; GONZÁLEZ TINTURÉ, Antónia; MORENO-GARCÍA, Marta; DIAS, Maria Isabel; PRUDÊNCIO, Maria Isabel - "Produção e consumo de cerâmica islâmica em Lisboa: conclusões de um projecto de investigação”. in Arqueologia Medieval. Porto. n. ${ }^{\circ} 10$ (2008), pp. 113-134.

BUGALHÃO, Jacinta; SOUSA, Maria João; GOMES, Ana Sofia - "Vestígios de produção oleira no Mandarim Chinês, Lisboa". in Revista Portuguesa de Arqueologia.

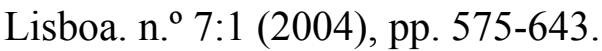

CALAIS, Cristina - "Outeiro de Povos: resultado preliminar das primeiras intervenções arqueológicas". in Cira. Vila Franca de Xira. n. 7 (1998), pp. 47-74.

CARVALHO, António Rafael; FARIA, João Carlos - "Cerâmicas muçulmanas do Museu Municipal de Alcácer do Sal”. in Arqueologia Medieval. Porto. n. 3 (1994), pp. 101-111.

Castelo de São Jorge. Núcleo Museológico. Lisboa: Câmara Municipal de Lisboa / EGEAC, EM, 2009.

CASMARRINHA, Helena Patrícia Saúde - Materiais Islâmicos do Sítio da Rua do Sembrano, Beja. Dissertação de mestrado em Arqueologia. Faculdade de Ciências Sociais e Humanas, Universidade Nova de Lisboa, 2013. Disponível em http://hdl.handle.net/10362/10250. 
A propósito da investigação sobre cerâmica islâmica em Portugal • Isabel Inácio, Constança dos Santos, Catarina Coelho, Marco Liberato, Ana Sofia Gomes, Jacinta Bugalhão, Helena Catarino, Sandra Cavaco, Jaquelina Covaneiro, Isabel Cristina Fernandes, Susana Gómez, Maria José Gonçalves

CATARINO, Helena - "O Castelo de Paderne (Albufeira: resultados da primeira intervenção arqueológica". in Arqueologia Medieval. Porto. n. 3 (1994), pp. 73-88.

CATARINO, Helena - "Arqueologia do período islâmico em Portugal: breve perspectiva". in O Arqueólogo Português. Lisboa. Série IV. 13/15 (1995/1997), pp. 457-484.

CATARINO, Helena - O Algarve Oriental durante a ocupação islâmica. Povoamento rural e recintos fortificados (Al-Ulyâ, n. o 6). Loulé, 3 Vol., 1997/1998.

CATARINO, Helena - “Arqueologia Medieval: o estado da 'arte' e novas perspectivas”. in ENCARNAÇÃO, José d' (ed.) - As Oficinas da História. Coimbra: Ed. Colibri/FLUC, 2002, pp. 131-148.

CATARINO, Helena - "Arqueologia da Antiguidade tardia e do período islâmico do Algarve na época de Estácio da Veiga”. in Xelb. Silves. n. 7 (2007), pp. 179-194.

CATARINO, Helena; CAVACO, Sandra; COVANEIRO, Jaquelina; FERNANDES, Isabel Cristina; GOMES, Ana; GÓMEZ MARTÍNEZ, Susana; GONÇALVES, Maria José; GRANGÉ, Mathieu; INÁCIO, Isabel; LOPES, Gonçalo; SANTOS, Constança dos; BUGALHÃO, Jacinta - "La céramique islamique du Ġarb al-Andalus: contextes socio-territoriaux et distribution". in Atti del IX Congresso Internazionale sulla Ceramica Medievale nel Mediterraneo. Venezia: Edizioni All'Insegna del Giglio, 2012, pp. 429-441.

CATARINO, Helena; INÁCIO, Isabel - "O Algarve Central”. in Arqueologia Medieval. Porto. n. ${ }^{o} 12$ (2012), pp. 155-161.

CATARINO, Helena; SANTOS, Constança dos - "A cerâmica Islâmica da Marca Inferior em território português". in Arqueologia Medieval. Porto. n. o 12 (2012), pp. 714.

CATARINO, Helena; COVANEIRO, Jaquelina; CAVACO, Sandra - “O Sotavento Algarvio". in Arqueologia Medieval. Porto. n. 12 (2012), pp. 147-154.

CAVACO, Sandra; COVANEIRO, Jaquelina; FERNANDES, Isabel Cristina GOMES, Ana; GÓMEZ MARTÍNEZ, Susana; GONÇALVES, Maria José; GRANGÉ, Mathieu; INÁCIO, Isabel; LOPES, Gonçalo; SANTOS, Constança dos; BUGALHÃO, Jacinta; 
A propósito da investigação sobre cerâmica islâmica em Portugal • Isabel Inácio, Constança dos Santos, Catarina Coelho, Marco Liberato, Ana Sofia Gomes, Jacinta Bugalhão, Helena Catarino, Sandra Cavaco, Jaquelina Covaneiro, Isabel Cristina Fernandes, Susana Gómez, Maria José Gonçalves

CATARINO, Helena - "O Gharb al-Andalus. Problemáticas e novos contributos em torno da cerâmica". in Arqueologia Medieval. Porto. 12 (2012), pp. 5-6.

CAVACO, Sandra Cristina da Costa Fialho Palma - $O$ arrabalde da Bela Fria: contributos para o estudo da Tavira islâmica. Dissertação de mestrado em Portugal Islâmico e o Mediterrâneo, Faculdade de Ciências Humanas e Sociais, Universidade do Algarve, 2011. http://hdl.handle.net/10400.1/3109.

COELHO, Catarina - "A ocupação islâmica do Castelo dos Mouros (Sintra): interpretação comparada". in Revista Portuguesa de Arqueologia. Lisboa. n. ${ }^{\circ}$ 3: 1 (2000), pp. 207-225.

COELHO, Catarina - "O Castelo dos Mouros (Sintra)". in FERNANDES, Isabel Cristina (ed.) - Mil anos de fortificações na Península Ibérica e no Magreb. Actas do Simpósio Internacional sobre Castelos. Palmela: Edições Colibri/Câmara Municipal de Palmela, 2002, pp. 389-395.

CORREIA, Fernando; PICARD, Cristophe - "Intervenção arqueológica no Castelo da Juromenha". in Arqueologia Medieval. Porto. n. ${ }^{\circ}$ (1992), pp. 71-89.

COUTINHO, Hélder M. R. - "Cerâmica Muçulmana no Montinho das Laranjeiras”. in Arqueologia Medieval. Porto. n. ${ }^{\circ} 2$ (1993), pp. 39-54.

COVANEIRO, Jaquelina; FERNANDES, Isabel Cristina GOMES, Ana; GÓMEZ MARTÍNEZ, Susana; GONÇALVES, Maria José; INÁCIO, Isabel; SANTOS, Constança dos; COELHO, Catarino; LIBERATO, Marco; BUGALHÃO, Jacinta; CATARINO, Helena; CAVACO, Sandra - "Cerâmica islâmica em Portugal: 150 anos de investigação". in Arqueologia em Portugal. 150 Anos. Lisboa: Associação dos Arqueólogos Portugueses, 2013, pp. 73-80.

DÉLÉRY, Claire - Dynamiques économiques sociales et cutureles d'al-Andalus à partir d'une étude de la céramique de cuerda seca (seconde moitié du Xe siècle-première moitié du XIII siècle). Tese de doutoramento. Toulouse. 7 Vols., 2006.

DÉLÉRY, Claire ; CHAPOULIE, R. ; DELAGUE, D. - “Contribution à l’étude de l'évolution technologique et du commerce des céramiques de cuerda seca en alAndalus ( $\left.\mathrm{X}^{\mathrm{o}}-\mathrm{XII}{ }^{\circ} \mathrm{S}\right)$ "'. in Actas del VIII Congreso internacional de cerámica medieval en el Mediterráneo. Ciudad Real: Asociación Española de Arqueología Medieval, 2009, pp. 571-597.

Medievalista online № 17। Ja ne iro - Junho 2015 (c) IEM - Instituto de Estudo s Me die va is 33 www2.fc sh.unl.pt/ ie $\mathrm{m} / \mathrm{me}$ die va lista 
A propósito da investigação sobre cerâmica islâmica em Portugal • Isabel Inácio, Constança dos Santos, Catarina Coelho, Marco Liberato, Ana Sofia Gomes, Jacinta Bugalhão, Helena Catarino, Sandra Cavaco, Jaquelina Covaneiro, Isabel Cristina Fernandes, Susana Gómez, Maria José Gonçalves

DIAS, Maria Isabel; PRUDÊNCIO, Maria Isabel; BUGALHÃO, Jacinta; GOMES, Sofia; SOUSA, Maria João; FOLGADO, Deolinda - "A produção de cerâmicas no arrabalde ocidental da Lisboa islâmica. Primeiros resultados arqueométricos”. in Promontoria Monográfica. Faro. 11 (2008), pp. 157-167.

DIAS, Maria Isabel; PRUDÊNCIO, Maria Isabel; GOUVEIA, Maria Ângela "Arqueometria de cerâmicas islâmicas das regiões de Lisboa, Santarém e Alcácer do Sal (Portugal): caracterização química e mineralógica”. in Garb, Sítios Islâmicos do Sul Peninsular. Lisboa: IPPAR/Junta de Extremadura, 2001, pp. 257-281.

DIAS, Maria Isabel; PRUDÊNCIO, Maria Isabel; GOUVEIA, Maria Ângela; GOMES Ana; GASPAR, Alexandra - "Tecnologias de produção de cerâmicas pintadas dos séculos XI a XII do Castelo de S. Jorge (Lisboa, Portugal)". in Actas del VIII Congreso Internacional de Cerámica Medieval en el Mediterráneo. Tomo II. Ciudad Real: Asociación Española de Arqueología Medieval, 2009, pp. 963-966.

DIOGO, João Manuel (ed.) - Actas das $4^{a_{5}}$ Jornadas de Cerâmica Medieval e PósMedieval: métodos e resultados para o seu estudo. Tondela: Câmara Municipal, 2008.

El esplendor de los Omeyas cordobeses. Catálogo de Piezas. Granada: El Legado Andalusí, 2001.

FABIÃO, Carlos; GUERRA, Amílcar - "Uma fortificação Omíada em Mesas do Castelinho (Almodôvar)". in Arqueologia Medieval. Porto. n. ${ }^{\circ} 2$ (1993), pp. 85-102.

FERNANDES, Isabel Cristina F. - "Uma taça islâmica com decoração antropomórfica proveniente do Castelo de Palmela". in Arqueologia Medieval. Porto. n. 6 (1999), pp. 79-99.

FERNANDES, Isabel Cristina F. (ed.) - Mil Anos de Fortificações na Península Ibérica e no Magreb (500-1500). Palmela: Ed. Colibri/Câmara Municipal de Palmela, 2002.

FERNANDES, Isabel Cristina F. - O Castelo de Palmela, do islâmico ao cristão. Lisboa: Edições Colibri/Câmara Municipal, 2004.

FERNANDES, Isabel Cristina F. - "Arqueologia Medieval em Portugal: 25 anos de investigação". in Portugália. Porto. Nova Série, Vol. XXVI (2005), pp. 149-173.

FERNANDES, Isabel Cristina; CARVALHO, António Rafael - "Cerâmicas muçulmanas do Castelo de Palmela". in Actes du VI Colloque International sur la 
A propósito da investigação sobre cerâmica islâmica em Portugal • Isabel Inácio, Constança dos Santos, Catarina Coelho, Marco Liberato, Ana Sofia Gomes, Jacinta Bugalhão, Helena Catarino, Sandra Cavaco, Jaquelina Covaneiro, Isabel Cristina Fernandes, Susana Gómez, Maria José Gonçalves

Céramique Médiévale in Méditerranée. Aix-en-Provence: Narrations Editions, 1997, pp. 327-335.

FERNANDES, Isabel Cristina; CARVALHO, António Rafael - "Elementos para o estudo da ruralidade muçulmana na região de Palmela". in Actas del II Congreso de Arqueología Peninsular. Zamora.1996. Zamora: 1999, pp. 517-526.

FERNANDES, Isabel Cristina; SANTOS, Michelle Teixeira (coord.) - Palmela Arqueológica: Espaços, Vivências, Poderes. Roteiro da Exposição. Palmela: Município de Palmela, 2008.

FERREIRA, Maria Mulize Neves - As formas de barrada/surayba na kura de uhsunuba ou de silb: um ensaio para o estudo das cerâmicas islâmicas do povoado da Portela 3. Tese de mestrado em Pré-História e Arqueologia, Universidade de Lisboa, Faculdade de Letras, 2009. http://hdl.handle.net/10451/490.

FILIPE, Vanessa Galiza - Contributo para o conhecimento da presença islâmica em Yãbura - estudo do espólio exumado nas intervenções arqueológicas do Museu Municipal de Évora. Dissertação de mestrado em Arqueologia, Faculdade de Ciências Sociais e Humanas, Universidade Nova de Lisboa, 2012. http://hdl.handle.net/10362/8109.

GAMITO, Teresa Júdice - O Algarve e o Magreb (711 - 1249). Faro: Universidade do Algarve, 2003.

GELICHI, Sauro (ed.) - Atti del IX Congresso Internazionale sulla Ceramica Medievale nel Mediterraneo. Venezia: Edizioni All'Insegna del Giglio, 2012.

GOMES, Mário Varela - "Cerâmicas islâmicas do poço da Hortinhola (Moncarapacho, Olhão)". in Actas das 2. ${ }^{a s}$ Jornadas de Cerâmica Medieval e Pós-Medieval. Métodos e resultados para o seu estudo. Tondela. 22 a 25 de Março de 1995. Tondela: Câmara Municipal, 1998, pp. 33-41.

GOMES, Rosa Varela - Cerâmicas Muçulmanas do Castelo de Silves (Xelb, 1). Silves, 1988.

GOMES, Rosa Varela - "Cerâmicas muçulmanas, orientais e orientalizantes do Castelo de Silves (peças esmaltadas, policromas e de reflexo metálico)". in Estudos Orientais. Lisboa. Vol. II (1991), pp. 13-39. 
A propósito da investigação sobre cerâmica islâmica em Portugal • Isabel Inácio, Constança dos Santos, Catarina Coelho, Marco Liberato, Ana Sofia Gomes, Jacinta Bugalhão, Helena Catarino, Sandra Cavaco, Jaquelina Covaneiro, Isabel Cristina Fernandes, Susana Gómez, Maria José Gonçalves

GOMES, Rosa Varela - "Cerâmicas medievais do Sul de Portugal. Qual o Estado da Questão?". in Actas das 1. as Jornadas de Cerâmica Medieval e Pós-Medieval. Métodos e resultados para o seu estudo. Tondela. 28 a 31 de Outubro de 1992. Tondela. Câmara Municipal, 1995, pp. 287-296.

GOMES, Rosa Varela - Silves (Xelb), uma cidade do Gharb al-Andalus: território e cultura (Trabalhos de Arqueologia, 23). Lisboa: Instituto Português de Arqueologia, 2002 .

GOMES, Rosa Varela - "O século XX e a Arqueologia Muçulmana em Portugal”. in Arqueologia \& História. Lisboa. 54 (2002), pp. 203-220.

GOMES, Rosa Varela - Silves (Xelb), uma cidade do Gharb al-Andalus: a Alcáçova (Trabalhos de Arqueologia, 35). Lisboa: Instituto Português de Arqueologia, 2004.

GOMES, Rosa Varela - Silves (Xelb), uma cidade do Gharb al-Andalus: o núcleo urbano (Trabalhos de Arqueologia, 44). Lisboa: Instituto Português de Arqueologia, 2006.

GOMES, Rosa Varela - Silves (Xelb), uma cidade do Gharb al-Andalus: a zona da Arrochela (Trabalhos de Arqueologia, 53). Lisboa: IGESPAR, 2011.

GOMES, Rosa Varela; GOMES, Mário Varela - "Cerâmicas estampilhadas muçulmanas e mudéjares, do poço-cisterna de Silves". in Actas do I Encontro Nacional de Arqueologia Urbana, Setúbal, 1985 (Trabalhos de Arqueologia, 3). Lisboa: IPPC, 1986, pp. 127-141.

GOMES, Rosa Varela; GOMES, Mário Varela - Palácio Almóada da Alcáçova de Silves. Catálogo da Exposição. Lisboa: Museu Nacional de Arqueologia, 2001.

GOMES, Rosa Varela; GOMES, Mário Varela (ed.) - Ribāt da Arrifana. Cultura material e espiritualidade. Aljezur: Associação de Defesa do Património Histórico e Arqueológico de Aljezur/Município de Aljezur, 2007.

GÓMEZ MARTÍNEZ, Susana - “Cerámica decorada islámica de Mértola - Portugal (s. IX-XIII)". in Actes du VI Congrès La céramique médiévale en Méditerranée. Aix-enProvence: Narration Éditions, 1997, pp. 311-325.

GÓMEZ MARTÍNEZ, Susana - "Cerâmica de verde e manganês do Castro da Cola”. in Actas das 2. ${ }^{a s}$ Jornadas de Cerâmica Medieval e Pós-Medieval. Métodos e resultados 
A propósito da investigação sobre cerâmica islâmica em Portugal • Isabel Inácio, Constança dos Santos, Catarina Coelho, Marco Liberato, Ana Sofia Gomes, Jacinta Bugalhão, Helena Catarino, Sandra Cavaco, Jaquelina Covaneiro, Isabel Cristina Fernandes, Susana Gómez, Maria José Gonçalves

para o seu estudo. Tondela. 22 a 25 de Março de 1995. Tondela: Câmara Municipal, 1998, pp. 57-65.

GÓMEZ MARTÍNEZ, Susana - “A Cerâmica no Gharb al-Ândaluz”. in Portugal Islâmico - Os últimos sinais do Mediterrâneo. Lisboa: Museu Nacional de Arqueologia, 1998, pp. 121-131.

GÓMEZ MARTÍNEZ, Susana - Cerámica Islámica de Mértola: producción y comercio. Madrid: Servicio de Publicaciones de la Universidad Complutense de Madrid, 2006.

http://cisne.sim.ucm.es/search*spi $\sim$ S7/X?SEARCH=susana+gomez+martinez\&search $\underline{\text { scope }=7 \& \text { SORT }=\mathrm{D}}$.

GÓMEZ MARTÍNEZ, Susana (ed.) - Al-Ândalus espaço de mudança. Balanço de 25 anos de história e arqueologia medievais. Seminário de Homenagem a Juan Zozaya Stabel-Hansen. Mértola: Campo Arqueológico de Mértola, 2006.

GÓMEZ MARTÍNEZ, Susana - "Reflexão crítica sobre o estado da investigação para o período medieval islâmico no Algarve". in Xelb. Silves. n. ${ }^{\circ} 10$ (2010), pp. 497-508.

GÓMEZ MARTÍNEZ, Susana (coord.) - Os Signos do Quotidiano: Gestos, Marcas e Símbolos no al-Ândalus. Catálogo da Exposição. Mértola: Campo Arqueológico de Mértola, 2011.

GÓMEZ MARTÍNEZ, Susana; ÁLVARO, Rocio; MARQUES, João António; GRILO, Carolina; LOPES, Gonçalo - "Evidências materiais da ocupação islâmica da margem direita do Guadiana”. in Xelb. Silves. n. 9 (2009), pp. 685-694.

GÓMEZ MARTÍNEZ, Susana; GRANGÉ, Mathieu; LOPES, Gonçalo - “A cerâmica islâmica no Alentejo". in Arqueologia Medieval. Porto. n. 12 (2012), pp. 109-119.

GONÇALVES, Luís Ribeiro - Sistemas de povoamento e organização territorial: dois vales na periferia de Lisboa: séculos IX-XIV. Tese de mestrado em História Medieval, Universidade de Lisboa, Faculdade de Letras, 2011. http://hdl.handle.net/10451/6873.

GONÇALVES, Maria José da Silva - Silves Islâmica: a muralha do arrabalde Oriental e a dinâmica de ocupação do espaço adjacente. Dissertação de mestrado em Teoria e Métodos da Arqueologia, Faculdade de Ciências Humanas e Sociais, Universidade do Algarve, 2008.

Medievalista online № 17। Ja ne iro - Junho 2015 (C) $\mathbb{E M}$ - Instituto de Estudos Me die va is 37 www2.fc sh.unl.pt/ ie $\mathrm{m} / \mathrm{me}$ die va lista 
A propósito da investigação sobre cerâmica islâmica em Portugal • Isabel Inácio, Constança dos Santos, Catarina Coelho, Marco Liberato, Ana Sofia Gomes, Jacinta Bugalhão, Helena Catarino, Sandra Cavaco, Jaquelina Covaneiro, Isabel Cristina Fernandes, Susana Gómez, Maria José Gonçalves

GONÇALVES, Maria José (ed.) - O Gharb no al-Andalus: sínteses e perspectivas de estudo. Homenagem a José Luís de Matos (Xelb, 9). Silves, 2009.

GONÇALVES, Maria José - "O Barlavento Algarvio". in Arqueologia Medieval. Porto. n. ${ }^{\circ} 12$ (2012), pp. 163-168.

HENRY, Sarah Hélène Christine - "Cuerda seca" Islamic ceramics from the X-XIIIth centuries of Mértola. Tese de Mestrado em Ciência e Engenharia dos Materiais, Universidade de Aveiro, 2012. http://hdl.handle.net/10773/10066.

LACERDA, Manuel; SOROMENHO, Miguel; RAMALHO, Maria Magalhães; LOPES, Carla (eds.) - Garb, Sítios Islâmicos do Sul Peninsular. Lisboa: IPPAR/ Junta de Extremadura, 2001.

Les Andalousies de Damas à Cordoue. Paris: Éditions Hazan/Institut du Monde Arabe, 2000.

LIBERATO, Marco António Antunes - A cerâmica pintada a branco na Santarém Medieval: uma abordagem diacrónica séculos XI a XVI. Tese de mestrado em Arqueologia, Universidade de Lisboa, Faculdade de Letras, 2012. http://hdl.handle.net/10451/6023.

LOPES, Conceição (dir.) - Lusa: a matriz portuguesa. Catálogo da exposição realizada no Rio de Janeiro, de 12 de Outubro de 2007 a 10 de Fevereiro de 2008. Em Brasília de 26 de Fevereiro a 4 de Maio de 2008 e em S. Paulo de 16 de Junho a 7 de Setembro de 2008. São Paulo: Mag Mais Rede Cultural. 2 Vols., 2007.

Los Jarrones de la Alhambra: simbología y poder. Exposición temporal Jarrones de la Alhambra. Granada: Patronato de la Alhambra y Generalife, 2007.

MACIAS, Santiago - Mértola islâmica - Estudo Histórico-Arqueológico do Bairro da Alcáçova (Séc. XII-XIII). Mértola: Campo Arqueológico de Mértola, 1996.

MACIAS, Santiago - Mértola - O último porto do Mediterrâneo. Mértola: Campo Arqueológico de Mértola. 3 vol, 2006.

MACIAS, Santiago; GÓMEZ MARTÍNEZ, Susana (dir.) - O Gharb Al-Ândalus. Problemáticas e novos contributos em torno da cerâmica, Mértola, 2009. Porto: Edições Afrontamento (Arqueologia Medieval, 12), 2012. 
A propósito da investigação sobre cerâmica islâmica em Portugal • Isabel Inácio, Constança dos Santos, Catarina Coelho, Marco Liberato, Ana Sofia Gomes, Jacinta Bugalhão, Helena Catarino, Sandra Cavaco, Jaquelina Covaneiro, Isabel Cristina Fernandes, Susana Gómez, Maria José Gonçalves

MAIA, Maria - "O Vaso de Tavira e o seu contexto". in Actas do Colóquio Internacional. Portugal, Espanha e Marrocos. O Mediterrâneo e o Atlântico. Faro. 2 a 4 de Novembro de 2000. Faro: Universidade do Algarve/Faculdade de Ciências Humanas e Sociais/Centro de Cultura Árabe, Islâmica e Mediterrânea, 2004, pp. 143166.

MAIA, Maria - Vaso de Tavira. Tavira: Câmara Municipal, 2012.

MAIA, Maria; FERNANDES, Carla; LOPES, Marco; CAVACO, Sandra (coord.) Tavira. Território e poder. Catálogo da Exposição. Lisboa: Museu Nacional de Arqueologia/Câmara Municipal de Tavira, 2003.

MAIA, Maria; MAIA, Manuel - Tavira Islâmica: Núcleo Islâmico. Tavira: Câmara Municipal, 2012.

MARQUES, João; GÓMEZ MARTÍNEZ, Susana; GRILO, Carolina; ÁLVARO, Rocío; LOPES, Gonçalo - "Cerâmica e povoamento rural medieval no troço médio-inferior do vale do Guadiana (Alentejo, Portugal)". in Atti del IX Congresso Internazionale sulla Ceramica Medievale nel Mediterraneo. Venezia, 2009. Venezia; Edizioni All'Insegna del Giglio, 2012, pp. 442-448.

MATOS, José Luís de - "Forno cerâmico (Cerro da Vila) - 1982". in Informação Arqueológica. Lisboa. n. ${ }^{\circ} 5$ (1985), p. 77.

MATOS, José Luís de - "Influências orientais na cerâmica muçulmana do Sul de Portugal". in Estudos Orientais. Lisboa. Vol. II (1991), pp. 75-83.

MATOS, José Luís de - "Cerâmicas muçulmanas do Castelo de Silves". in Arqueologia Medieval. Mértola, n. ${ }^{\circ} 1$ (1992), pp. 229-230.

PAIXÃO, António; FARIA, João Carlos; CARVALHO, António Rafael - “O Castelo de Alcácer do Sal. Um projecto de arqueologia urbana". in Encontro de Arqueologia Urbana (Bracara Augusta, vol. XLV. n. 97 (110). Braga, 1994, pp. 215-264.

PAULO, Luís Campos - “O simbolismo da purificação. O 'Vaso de Tavira': iconografia e interpretação". in Revista Portuguesa de Arqueologia. Lisboa. n. ${ }^{\circ}$ 10: 1 (2007), pp. 289-316. 
A propósito da investigação sobre cerâmica islâmica em Portugal • Isabel Inácio, Constança dos Santos, Catarina Coelho, Marco Liberato, Ana Sofia Gomes, Jacinta Bugalhão, Helena Catarino, Sandra Cavaco, Jaquelina Covaneiro, Isabel Cristina Fernandes, Susana Gómez, Maria José Gonçalves

RIBEIRO, Margarida - "Património cerâmico e linguístico português sob influência islâmica". in A Cerâmica Medieval no Mediterrâneo. Lisboa, 1987. Mértola: Campo Arqueológico de Mértola, 1991, pp. 491-496.

ROCHA, António Santos - "Notícia de alguns silos e louças árabes do Algarve". Boletim da Sociedade Archeologica Santos Rocha. Figueira da Foz Vol. I: 1 (1904), pp. 20-21.

ROCHA, António Santos - Memórias e explorações arqueológicas. Memórias sobre a Antiguidade. (Acta Universitatis Conimbrigensis, Vol. II). Coimbra: Biblioteca Geral da Universidade de Coimbra, 1971.

RODRIGUES, Patrícia de Freitas Lopes - Cerâmicas medievais do morro da Sé de Viseu: Fossas-lixeiras do pátio do Museu Grão Vasco. Tese de mestrado em Museologia, Universidade de Coimbra, Faculdade de Letras, 2012.

RODRIGUES, Severino; CABRAL, João - "Silos medievais de Caparide". in Arquivo de Cascais. Cascais. n. 9 (1990), pp. 63-73.

ROSSELLÓ BORDOY, Guillermo - Ensayo de sistematización de la cerámica árabe en Mallorca. Palma de Mallorca, 1978.

SABROSA, Armando; ESPÍRITO SANTO, Paulo - “Almada Medieval/Moderna, um projecto de investigação". in Al-madan. Almada. 2. Série, n. ${ }^{\circ} 1$ (1992), pp. 5-12.

SANTOS, Heloísa Valente dos; ABRANCHES, Paula Barreira - "Ocupações do período Medieval e Moderno nos concelhos de Moura e Mourão". in Al-Madan. Almada. 2. ${ }^{\text {a }}$ série, n. ${ }^{\circ} 11$ (2002), pp. 152-157.

SERRANO, Liliana Isabel Marques - Lucernas, candis e candeias: para uma distribuição geográfica no território português. Dissertação de mestrado em Arqueologia e Território (Arqueologia Medieval), Faculdade de Letras da Universidade de Coimbra, 2011. http://hdl.handle.net/10316/19172.

Sesimbra. Guia do Museu Arqueológico de Sesimbra. Sesimbra: Câmara Municipal, 1960.

SILVA, Carlos Jorge Rodrigues - Estudo dos materiais da Avenida 5 de Outubro, $n^{\circ} 2$ a 8 em Santarém. Dissertação de mestrado em Arqueologia e Ambiente, Universidade de Évora, 2008.

Medievalista online № 17 I Ja ne ir - Junho $2015 \odot \mathbb{E M}$ - Instituto de Estudo s Me die vais 40 www2.fc sh.unl.pt/ ie $\mathrm{m} / \mathrm{me}$ die va lista 
A propósito da investigação sobre cerâmica islâmica em Portugal • Isabel Inácio, Constança dos Santos, Catarina Coelho, Marco Liberato, Ana Sofia Gomes, Jacinta Bugalhão, Helena Catarino, Sandra Cavaco, Jaquelina Covaneiro, Isabel Cristina Fernandes, Susana Gómez, Maria José Gonçalves

SILVA, Luís Alves da; MATEUS, Rui (eds.) - Actas do IV Congresso Internacional A cerâmica medieval no Mediterrâneo Ocidental. Mértola: Campo Arqueológico de Mértola, 1991.

SILVA, Marta Cristina de São Marcos Inácio da - A cerâmica islâmica da Alcáçova de Santarém, das unidades estratificadas 17, 18, 27, 30, 39, 41, 193, 195, 196, 197 e 210. Tese de mestrado em Arqueologia, Faculdade de Letras da Universidade de Lisboa, 2011. http://hdl.handle.net/10451/5361.

SIMÃO, Inês Sofia - Uma habitação no arrabalde de Silves: cerâmicas islâmicas da Casa II, no Teatro Gregório Mascarenhas. Dissertação de Mestrado em Estudos do Património, Universidade Aberta, 2008. http://hdl.handle.net/10400.2/2590.

TEICHNER, Félix - "Acerca da Vila Romana de Milreu/Estoi. Continuidade da ocupação na época árabe”. in Arqueologia Medieval. Porto. n. 3 (1994), pp. 89-100.

TEICHNER, Félix - “A ocupação do centro da cidade de Évora da época romana à contemporânea. Primeiros resultados da intervenção do Instituo Arqueológico Alemão". in Actas das 2. "as Jornadas de Cerâmica Medieval e Pós-Medieval. Métodos e resultados para o seu estudo. Tondela. 22 a 25 de Março de 1995. Tondela: Câmara Municipal de Tondela, 1998, pp. 17-31.

TORRES, Cláudio - Cerâmica islâmica portuguesa. Catálogo. Mértola: Campo Arqueológico de Mértola, 1987.

TORRES, Cláudio - "Lisboa muçulmana. Um espaço urbano e o seu território". in Lisboa Subterrânea. Lisboa, Instituto Português de Museus, 1994, pp. 80-85.

TORRES, Cláudio - O Vaso de Tavira. Uma proposta de interpretação. Mértola: Campo Arqueológico de Mértola, 2004.

TORRES, Cláudio; MACIAS, Santiago - “A Arte Islâmica no Ocidente Andaluz”. in PEREIRA, Paulo - História da Arte Portuguesa. Vol. 1. Lisboa: Círculo de Leitores, 1995, pp. 150-177.

TORRES, Cláudio; MACIAS, Santiago - O legado islâmico em Portugal. Lisboa: Círculo de Leitores, 1998.

TORRES, Cláudio; MACIAS, Santiago (dir.) - Portugal Islâmico. Os últimos sinais do Mediterrâneo. Lisboa: Museu Nacional de Arqueologia, 1998. 
A propósito da investigação sobre cerâmica islâmica em Portugal • Isabel Inácio, Constança dos Santos, Catarina Coelho, Marco Liberato, Ana Sofia Gomes, Jacinta Bugalhão, Helena Catarino, Sandra Cavaco, Jaquelina Covaneiro, Isabel Cristina Fernandes, Susana Gómez, Maria José Gonçalves

TORRES Cláudio; MACIAS, Santiago (coord.) - Museu de Mértola. Arte Islâmica.

Mértola: Campo Arqueológico de Mértola, 2001.

TORRES, Nádia Ferreira - O desenho na cerâmica islâmica de Mértola. Mértola: Campo Arqueológico de Mértola, 2011.

VASCONCELOS, José Leite - "Candeias árabes do Algarve". in O Archeologo Portuguez. Lisboa. Vol. VII (1902), pp. 119-125.

VASCONCELOS, José Leite - "Excursão arqueológica à Extremadura Transtagana”. in O Archeologo Portuguez. Lisboa. Vol. XIX (1914), pp. 300-323.

VASCONCELOS, José Leite - “Coisas Velhas". in O Archeologo Portuguez. Lisboa. Vol. XXII (1917), pp. 107-169.

VASCONCELOS, José Leite - "Excursão pelo Baixo Alentejo". in O Archeologo Portuguez. Lisboa. Vol. XXIX (1933), pp. 230-246.

VEIGA, Sebastião Philippes Martins Estácio da - Memoria das antiguidades de Mértola observadas em 1877 e relatadas por... Lisboa: Imprensa Nacional, 1880.

VEIGA, Sebastião Philippes Martins Estácio da - Antiguidades monumentaes do Algarve. Vol. II. Lisboa: Imprensa Nacional, 1887.

VEIGA, Sebastião Philippes Martins Estácio da - Antiguidades Monumentaes do Algarve. Vol. III. Lisboa: Imprensa Nacional, 1889.

VIANA, Abel - "Museu regional de Beja. Alguns objectos da Idade do Bronze, da Idade do Ferro e da Época Romana; cerâmica argárica; cerâmica árabe". in Arquivo de Beja. Beja. Vol. II (1945), pp. 309-339.

VIANA, Abel - "Castro de Nossa Senhora da Cola (Ourique)". in Arquivo de Beja. Beja. Vol. XV (1958), pp. 25-35.

VIANA, Abel - "Notas históricas, arqueológicas e etnográficas do Baixo Alentejo. 1. Castro de Nossa Senhora da Cola". in Arquivo de Beja. Beja. Vol. XVI (1959), pp. 324.

VIANA, Abel - "Notas históricas arqueológicas e etnográficas do Baixo Alentejo. Senhora da Cola". in Arquivo de Beja. Beja. Vol. XVII (1960), pp. 138-226. 
A propósito da investigação sobre cerâmica islâmica em Portugal • Isabel Inácio, Constança dos Santos, Catarina Coelho, Marco Liberato, Ana Sofia Gomes, Jacinta Bugalhão, Helena Catarino, Sandra Cavaco, Jaquelina Covaneiro, Isabel Cristina Fernandes, Susana Gómez, Maria José Gonçalves

VIANA, Abel - Algumas Noções Elementares de Arqueologia Prática. Beja: Livros Suméria, 1962.

VIANA, Abel; FORMOSINHO, José; FERREIRA, Octávio da Veiga - "De lo prerromano a lo árabe en el Museu Regional de Lagos”. in Archivo Español de Arqueologia. Madrid. Vol. XXVI (1953), pp. 113-138.

VIEGAS, Catarina; ARRUDA, Ana Margarida - "Cerâmicas Islâmicas da Alcáçova de Santarém". in Revista Portuguesa de Arqueologia. Lisboa. n. o 2: 2 (1999), pp. 105186.

ZOZAYA STABEL-HANSEN, Juan; RETUERCE VELASCO, Manuel; HERVÁS HERRERA, M. Á.; DE JUAN GARCÍA, A. (eds.) - Actas del VIII Congreso Internacional de Cerámica Medieval en el Mediterráneo. 2 Tomos. Ciudad Real: Asociación Española de Arqueología Medieval, 2009.

\section{COMO CITAR ESTE ARTIGO}

\section{Referência electrónica:}

INÁCIO, Isabel; SANTOS, Constança dos; COELHO, Catarina; LIBERATO, Marco; GOMES, Ana Sofia; BUGALHÃO, Jacinta; CATARINO, Helena; CAVACO, Sandra; COVANEIRO, Jaquelina; FERNANDES, Isabel Cristina; GÓMEZ, Susana; GONÇALVES, Maria José - “A propósito da investigação sobre cerâmica islâmica em Portugal". Medievalista [Em linha]. N. 17 (Janeiro - Junho 2015). [Consultado 01.01.2015].

http://www2.fcsh.unl.pt/iem/medievalista/MEDIEVALISTA17/isabelinacio1703.html ISSN 1646-740X. 
A propósito da investigação sobre cerâmica islâmica em Portugal • Isabel Inácio, Constança dos Santos, Catarina Coelho, Marco Liberato, Ana Sofia Gomes, Jacinta Bugalhão, Helena Catarino, Sandra Cavaco, Jaquelina Covaneiro, Isabel Cristina Fernandes, Susana Gómez, Maria José Gonçalves

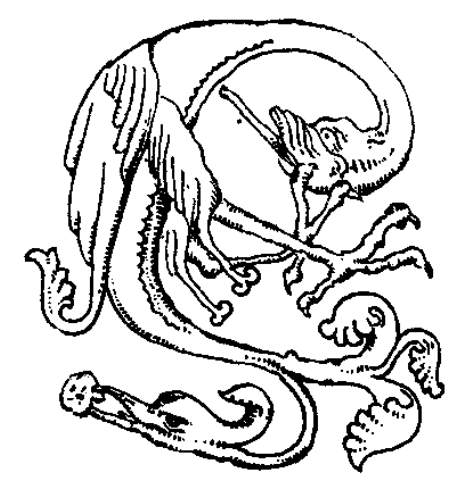

